\title{
Cerámicas del interior de Galicia desde el tardoimperio a la Alta Edad Media (s. v-x/XI d. n. e.): algunos casos de estudio
}

\author{
Pottery from inland Galicia from the Late Empire \\ to Early Medieval period (5th-10th/11th c. AD): \\ Some case studies
}

Carlos Tejerizo-García

Universidad del País Vasco. Facultad de Letras

Paseo de la Universidad, 5, E-01006 Vitoria-Gasteiz

carlosteje@gmail.com

\section{Francisco Alonso Toucido}

Universidade de Santiago de Compostela. Tempos Arqueólogos SL

Av. Lugo, 13, 2 C, E-36940 Cangas do Morrazo (Pontevedra)

franalonsotoucido@hotmail.com

\section{Diego Torres Iglesias}

Universidade de Vigo

Gontade, 1, E-36679 Piñeiro, Cuntis (Pontevedra)

dtorres.ig@gmail.com

En este artículo se presentan un conjunto de contextos cerámicos provenientes del interior del actual territorio de Galicia desde los momentos finales del Imperio romano hasta la Alta Edad Media. Estos han sido estudiados a partir del análisis morfotecnológico de diversos contextos estratigráficos de cinco yacimientos recientemente excavados. De esta forma, el objetivo principal de este artículo es el de ofrecer un marco comparativo que permita una mejor caracterización cronológica y social de los yacimientos de un período que, des del punto de vista historiográfico, ha sido escasamente tratado en el contexto del noroeste peninsular. 
This paper presents a group of pottery contexts from a number of different rural contexts from the interior of the present day province of Galicia dating to between the end of the Roman Empire and the Early Middle Ages. This study merges the formal and technological analyses of a diverse assemblage of stratigraphical contexts from five selected, recently excavated sites. Thus the main aim of the paper is to offer a comparative framework which offers a better chronological and social characterization of those sites for a period that, from a historiographical point of view, have been scarcely addressed in the context of northwestern Iberia.

\section{KEYWORDS}

POTTERY, EARLY MIDDLE AGES, GALICIA, CHAÎNES OPÉRATOIRES, RURAL WORLD

\section{Introducción}

La cerámica es, sin duda, uno de los principales materiales que mejor han permitido visibilizar, caracterizar e interpretar arqueológicamente el complejo período correspondiente a la transición entre el mundo antiguo y el medieval (Tejerizo García y Quirós Castillo, 2018). Su estudio marcó uno de los hitos principales en la configuración de la arqueología medieval en la península ibérica ya desde sus inicios como disciplina (Gutiérrez González y Bohigas Roldán, 1989; Riu Riu, 1977) y, en los últimos años, los análisis sobre este material han crecido exponencialmente. Un auge cuyo origen se encuentra en los cientos de intervenciones que han tenido lugar en los últimos veinte años, sumado a un nutrido número de proyectos de investigación específicamente dirigidos al tema (Vigil-Escalera, 2018). Muestra de ello son varios volúmenes recientes que recopilan las investigaciones más punteras a este respecto (De Man y Tente, 2014; Grassi y Quirós Castillo, 2018; Martín Viso, et al., 2018; Vigil-Escalera y Quirós Castillo, 2016). Estos recientes avances permiten no sólo datar con un alto grado de precisión los contextos de este período, sino también profundizar en los aspectos tecnológicos, sociales, económicos y políticos vinculados a la producción, consumo y distribución de este objeto tan necesario para las sociedades preindustriales (Kramer, 1985). Sin embargo, esto sólo es posible si existen secuencias y seriaciones cerámicas sólidas que establezcan un punto de comparación para los nuevos yacimientos excavados.

Si bien estas secuencias y seriaciones cerámicas están bien establecidas en territorios como Madrid, Cataluña, País Vasco o el suroeste peninsular, el caso de Galicia es algo distinto. Aunque se han realizado algunos pioneros intentos (ver apartado siguiente), a día de hoy no existen referencias sólidas que permitan establecer un punto de comparación para los materiales provenientes de las excavaciones, como ya ha sido comentado por otros autores (Fernández Fernández y Bartolomé Abraira, 2016: 105; Sánchez Pardo, 2010). Este vacío en la investigación conlleva algunos problemas interpretativos. Así, por ejemplo, aquellos yacimientos cuyos materiales no corresponden al período romano, mejor 
conocido, o a un claro contexto medieval o moderno, son clasificados reiteradamente bajo categorías muy laxas como "galaico-romano", "tardorromano" o "romano-medieval», lo que ocasiona interpretaciones circulares o muy deterministas.

Este panorama está cambiando en los últimos años en el contexto de Galicia por tres motivos principales. El primero es la ampliación de la masa de datos disponible mediante la excavación de numerosos contextos durante el período de auge de la arqueología comercial en Galicia —y, en particular, de la denominada "arqueología de la gasificación», entre finales de los años 90 e inicios del siglo XXI- hasta nuestros días (Criado Boado, et al., 1998). El segundo motivo es la publicación de un número muy significativo de trabajos pioneros en torno a la arqueología de este período en general, y a la cerámica en particular, que han renovado la disciplina por completo (Sánchez Pardo y Rodríguez Resino, 2009). Por último, la introducción de nuevas metodologías de trabajo en el estudio de la cerámica altomedieval, con especial mención a la arqueometría, que están empezando a ser aplicadas con estimulantes resultados (Prieto Martínez, et al., 2018b). Por lo tanto, actualmente contamos con todos los elementos para confrontar con un alto grado de rigurosidad el vacío que supone el estudio de la cerámica en Galicia entre los siglos v y x d. n. e.

En el contexto de varios proyectos de investigación ${ }^{1}$, tuvimos la oportunidad de revisar la secuencia estratigráfica y el repertorio cerámico de un nutrido grupo de yacimientos datados en el período objeto de estudio. De estos, presentamos aquí los resultados obtenidos en cinco de ellos, a través de los cuales se pueden sugerir algunas primeras propuestas de secuenciación cerámica de los contextos rurales del noroeste peninsular en el período comprendido entre el siglo v y el x/XI d. n. e. Este estudio es el resultado de un análisis exhaustivo y combinado de las producciones cerámicas documentadas en cada uno de los yacimientos, cuya datación ha sido propuesta mediante una combinación de los datos previamente existentes de cada uno de los yacimientos, el análisis de las producciones cerámicas diagnósticas de cada uno de ellos y su comparación con otros contextos mejor conocidos. Por su parte, la metodología de estudio cerámico aplicada en ellos ha sido la misma —salvo en el caso del yacimiento de A Pousada, por los motivos que luego se comentarán-. Partiendo de los principios de la antropología de la tecnología desarrollada por P. Lemonnier (Lemonnier, 1992), se revisaron todos los fragmentos cerámicos de cada unidad estratigráfica, diferenciando las cadenas tecnológico-productivas (CTO) presentes, en base tanto a sus características morfológicas como tecnológicas. Una vez diferenciadas las producciones, estas fueron cuantificadas siguiendo el sistema de doble registro proveniente del ámbito anglosajón, atendiendo al número de fragmentos y el peso en gramos. Esta cuantificación permite analizar la importancia de una producción dentro del conjunto total, aspecto esencial para determinar, por ejemplo, la datación de los conjuntos en el período que aquí nos ocupa (Adroher Auroux, et al., 2016; Vigil-

1. Concretamente, el proyecto postdoctoral «Sputnik Labrego. Resiliencia e resistencia da sociedade labrega galega en 'momentos de perigo': unha análise antropolóxica e arqueolóxica na longa duración», financiado por la Xunta de Galicia y dirigido por C. Tejerizo, y la investigación para la realización de la tesis doctoral «Cerámica medieval galega, características, uso e evolución da producción», de F. Alonso y dirigida por P. Prieto. 
Escalera, 2006). En términos morfológicos y de descripción decorativa, se han seguido las propuestas establecidas por los principales referentes del estudio cerámico del período medieval, tanto en la península ibérica como en Europa (Coll Conesa, 2011; Orton, et al., 1997; VV. AA., 1998). De esta forma, una vez determinadas las principales CTO de cada yacimiento, se ponían en comparación con el resto, determinando las producciones presentes y su contextualización estratigráfica y estableciendo una secuencia relativa entre ellas, lo que ha permitido una primera aproximación en términos cronológicos a las cadenas tecnológicas, las cuales, a su vez, se establecen como una base comparativa para futuros estudios.

\section{Apuntes sobre la historiografía de la cerámica medieval en Galicia}

El objetivo de este apartado no es el de realizar un análisis historiográfico exhaustivo sobre el desarrollo de los estudios cerámicos en el noroeste peninsular en general y en Galicia en particular, sino presentar una síntesis razonada de los principales hitos como marco referencial para nuestro propio trabajo. Por ello es importante destacar que, dentro del panorama historiográfico peninsular, Galicia es uno de los territorios donde la arqueología medieval ha tenido una menor proyección desde el punto de vista de la investigación académica (Acuña Castroviejo, et al., 2012; Xusto Rodríguez y Eguileta Franco, 1992). Es por ello que los estudios cerámicos son reducidos y están centrados, sobre todo, en los períodos pleno y bajomedieval. Esta situación se agrava en tanto en cuanto las actuaciones provenientes de las excavaciones de urgencia rara vez se publican, permaneciendo inéditas en una literatura gris que es un lugar común en la arqueología medieval peninsular (Quirós Castillo, 2018).

Desde finales del siglo xIX, con las excavaciones ejecutadas en la catedral de Santiago de Compostela por el canónigo López Ferreiro como un hito fundador, hasta los años 80 del siglo xx son varias las intervenciones realizadas en contextos medievales, si bien pocas de las publicaciones se centraron en los conjuntos cerámicos. Algunas excepciones son los trabajos de Manuel Chamoso Lamas y José Guerra Campos en la catedral compostelana, o los trabajos del primero en Iria Flavia (Padrón) y Torres de Oeste (Catoira) (Chamoso Lamas, 1951, 1972-1974). Habrá que esperar hasta 1975 para que se publique la primera síntesis sobre cerámica medieval gallega por parte de Francisco Fariña Busto (Fariña Busto, 1975). En este trabajo se identifican dos tipos de producciones: una a torno, con superficies cuidadas, pastas claras y con algún engobe rojo; y otra producción "gris perla», realizada a torneta. Tras esta primera síntesis, se realizan nuevas intervenciones en yacimientos medievales, si bien con referencias escasas a las cerámicas o sin una perspectiva estratigráfica, como ocurre por ejemplo con las excavaciones en la torre bajome- 
dieval de Meira (Moaña) (Acuña Fernández, et al., 1976), la intervención en Ouvigo (Os Blancos) (Rodríguez Colmenero, et al., 1985) o en el castillo bajomedieval de Soutomaior (Soutomaior) (De la Peña Santos, 1985).

En 1988, Fariña Busto y Suárez Otero realizan una nueva propuesta de secuenciación cerámica, estableciendo tres grupos de producciones en función de su cronología: en primer lugar, un grupo heterogéneo para las cerámicas comprendidas entre los siglos IX y XI; en segundo lugar, producciones «gris perla» para la Plena Edad Media; y, en último lugar, recipientes grises con elementos de importación de producciones vidriadas, en la Baja Edad Media (Fariña Busto y Suárez Otero, 1988; Martínez Peñín, 2013). Un año después, dentro del volumen La cerámica medieval en el norte y noroeste de la Península Ibérica: aproximación a su estudio (Gutiérrez González y Bohigas Roldán, 1989), se realiza una síntesis de la cerámica gallega en la que se afirma que entre los siglos IX y XI las cerámicas suelen contar con unas características pastas rojizas o acastañadas heterogéneas, realizadas a mano y con bruñido exterior. A partir del siglo xI la cerámica se homogeneizará en torno a producciones de coloración variada en grises, entre los que destacará el «gris perla», y se documentará por primera vez el torno alto como sistema de producción (Suárez Otero, et al., 1989: 287).

Si bien en los años 1990 las secuencias cerámicas medievales en Galicia no serán objeto de una revisión exhaustiva, sí que se avanza en la detección de nuevas producciones para este período. Será en 1993 cuando se publique un tipo cerámico poco común en Galicia, las jarras engobadas y decoradas con líneas de pintura blanca, cuya cronología rondaría el siglo XIII, y ese mismo año aparecerá el primer trabajo sobre cerámica vidriada bajomedieval (Suárez Otero, 1993). Diez años más tarde verá la luz el estudio de los materiales cerámicos del castillo de A Lúa, en Rianxo, siendo una de las publicaciones fundamentales para comprender la cerámica bajomedieval gallega (César Vila y Bonilla Rodríguez, 2003), entre cuyo repertorio destacan las ollas de borde horizontal cóncavo y las ollas de borde de pestaña. A este estudio se le suma posteriormente el trabajo realizado en el lazareto medieval de San Lázaro, en Santiago de Compostela, donde se recupera un importante conjunto de cerámica «gris perla», plenomedieval (Bonilla Rodríguez y César Vila, 2005).

El cambio de milenio resultará fructífero para la cerámica medieval gallega, pero también para las secuencias cerámicas más tempranas en el intervalo cronológico que aquí analizamos. Así, será entonces cuando se publiquen los estudios del material recuperado en la fortaleza de Rocha Forte (Santiago de Compostela) (Martínez Casal, 2006), así como los primeros trabajos sobre cerámica de importación bajomedieval (Caramés Moreira, et al., 2006) o las primeras sistematizaciones del conocimiento sobre las producciones de sigillata (César Vila, et al., 2010). Por su parte, será en esta primera década del siglo XxI cuando aparece el fundamental trabajo de Enrique Alcorta sobre las producciones lucenses, auténtico referente para el análisis de las transformaciones en la producción cerámica durante el fin del Imperio romano en Occidente (Alcorta Irastorza, 2001). Igualmente, fueron muy relevantes las excavaciones llevadas a cabo en el puerto de Vigo (Fernández Fernández, 2014), 
que fue el impulsor de la que puede ser considerada la única propuesta de secuenciación de la cerámica entre los siglos v y viI d. n. e. en el territorio gallego (Fernández Fernández y Bartolomé Abraira, 2016).

En 2010 se realiza una nueva propuesta de síntesis cerámica de las producciones desde la Plena Edad Media a la Baja Edad Media, incorporando algunas dataciones absolutas (César Vila, et al., 2010). A partir de este momento se realizarán las primeras analíticas arqueométricas a conjuntos medievales (Prieto Martínez, et al., 2010), que se han aplicado a otros contextos en los últimos años (Prieto Martínez, et al., 2018a, 2018b).

En los últimos años, el número de publicaciones sobre conjuntos cerámicos en Galicia del período que nos ocupa ha sido escaso, pero no inexistente. En el año 2013 se publica el estudio cerámico de una intervención realizada en la calle del Franco, en Santiago de Compostela. En el mismo se realiza una aproximación a la cerámica plenomedieval de la ciudad (Alonso Toucido, et al., 2014), a la que se le sumarán posteriormente aportaciones desde una óptica supralocal (Alonso Toucido, 2015). Así mismo, ese mismo año se publica un importante trabajo de sistematización de las producciones de terra sigillata hispánica tardía (TSHT) localizadas en territorio gallego (López Pérez, et al., 2013). Más recientemente ha visto la luz un trabajo sobre el excepcional conjunto de 120 jarritas bajomedievales de Augas Santas (Allariz) (Prieto Martínez, et al., 2019), así como un importante trabajo sobre el yacimiento de Cova Eirós (Triacastela) (César Vila, et al., 2018), junto con algunos trabajos sobre distintos contextos tardoimperiales (Alcorta Irastorza y Bartolomé Abraira, 2012; Tejerizo García, et al., 2018).

\section{Análisis de la secuencia estratigráfica y de los repertorios cerámicos}

En el próximo apartado presentaremos los principales datos de la revisión de cinco yacimientos dentro de la actual Comunidad Autónoma de Galicia (fig. 1). Todos ellos se caracterizan por presentar cronologías inscritas dentro del intervalo de los siglos $\mathrm{V}$-X/XI d. n. e. - tanto las otorgadas por los excavadores originalmente como las que finalmente se proponen en el presente trabajo-, haber sido excavados con metodología estratigráfica, así como por su carácter rural. Las características principales de estos asentamientos se resumen en la tabla 1.

De cada yacimiento nos centraremos en tres aspectos fundamentales: cuantificación y descripción de las cadenas tecnológicas, descripción de las principales formas documentadas y caracterización de los aparatos decorativos. Estas tres variables nos permitirán no sólo poner en comparación estos yacimientos entre sí y con otros del entorno, sino establecer una secuenciación relativa entre ellos, metodología que ha 


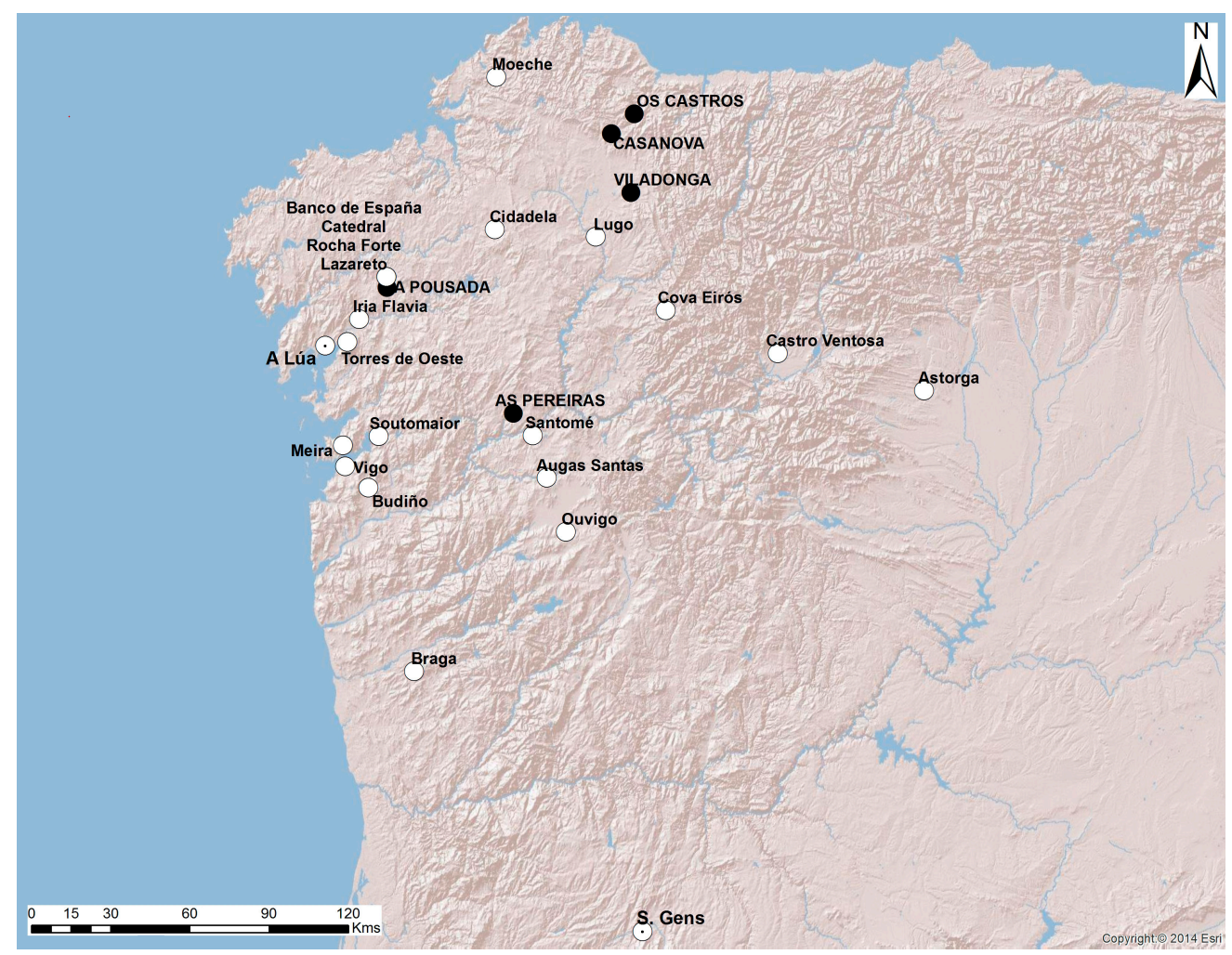

Figura 1. Yacimientos objeto de estudio y otros sitios mencionados en el trabajo.

sido muy útil en el estudio de este tipo de cerámicas en yacimientos similares de otras regiones (Tejerizo García, 2016; Vigil-Escalera, 2003, 2006, 2007). Lo que se presenta aquí, por tanto, son los resultados del estudio en conjunto de toda la estratigrafía del yacimiento, agrupando y caracterizando todas las cadenas tecnológicas documentadas en cada sitio.

Tabla 1. Características principales de los yacimientos analizados

\begin{tabular}{|c|c|c|c|c|}
\hline Nombre & Tipo de asentamiento & Año de excavación & $\begin{array}{c}\text { Fragmentos } \\
\text { cerámicos analizados }\end{array}$ & $\begin{array}{l}\text { Peso total } \\
(\mathbf{k g})\end{array}$ \\
\hline Viladonga & Asentamiento fortificado & Distintas campañas desde los años 70 & 5.751 & 110,7 \\
\hline Os Castros & Asentamiento rural abierto & 2017 & 124 & 3,2 \\
\hline Casanova & Asentamiento rural abierto tipo aldea & 2008 y 2009 & 415 & 3,03 \\
\hline A Pousada & Asentamiento rural abierto tipo granja & 2001 & 45 & \\
\hline As Pereiras & Asentamiento rural abierto & 1998 & 2.133 & 25,8 \\
\hline
\end{tabular}




\subsection{Castro de Viladonga (Castro de Rei, Lugo): finales s. IV - inicios s. vi d. n. e.}

El castro de Viladonga pasa por ser uno de los yacimientos más señeros de toda la historiografía del noroeste peninsular. Situado a $22 \mathrm{~km}$ al noreste de la ciudad de Lugo, se encuentra en el límite oriental de la llamada Terra Chá. Su posición privilegiada le otorga un gran dominio visual de la zona. El substrato geológico está formado por pizarras de Cándana y areniscas, con la presencia de intercalaciones de rocas calcáreas y magnesitas a apenas $300 \mathrm{~m}$ al sur. Este yacimiento de 4 hectáreas de extensión —de los cuales $8.000 \mathrm{~m}^{2}$ corresponderían a la croa- pasa por ser uno de los asentamientos fortificados más excavados en extensión, cerca de $6.600 \mathrm{~m}^{2}$. Esta gran extensión excavada es consecuencia de una historiografía muy particular y de intervenciones reiteradas sobre el sitio desde los años 70 hasta la actualidad, con una propuesta de datación cronológica por parte de sus excavadores desde la Prehistoria Reciente hasta el siglo vi d. n. e. (véase una síntesis en Arias Vilas, et al., 2013: 23-34).

Durante el año 2017 tuvimos la ocasión de revisar el material cerámico de las últimas seis campañas de excavación del sitio, un total de 5.751 fragmentos con un peso total de 110,7 kg, lo que nos permitió realizar una nueva propuesta de secuenciación estratigráfica del yacimiento (Tejerizo García, et al., 2019). Así, pudimos establecer hasta cuatro fases principales de ocupación y de abandono, de las cuales la tercera se correspondería con una reocupación del sitio, que datamos entre finales del siglo iv e inicios del siglo vi d. n. e. Esta fase se caracterizaría por una reocupación del castro tras, al menos, dos siglos de abandono, lo que supuso la reconstrucción completa de las unidades domésticas, del entramado urbano interior y de las fortificaciones (Tejerizo García, et al., 2019). De esta tercera fase de ocupación del sitio pudimos revisar un total de 2.431 fragmentos cerámicos con un peso de $51,8 \mathrm{~kg}$, distinguiendo un total de 9 CTO, que se describen en la tabla 2 (Tejerizo García, et al., 2018b).

Lo más significativo del conjunto de Viladonga es la gran variedad de producciones cerámicas. Entre ellas, cabe destacar la presencia de un pequeño conjunto de sigillatas tardías (5\% de los fragmentos y 1,36 \% del peso), cuyas decoraciones, sobre todo la presencia de estampillados, mostrarían una ocupación del sitio ya dentro de la quinta centuria, sin descartar que ya fuera ocupado en los últimos estadios de la cuarta (Vigil-Escalera, 2013). A este momento cronológico corresponderían también otro tipo de producciones, como la presencia, mínima, de cerámicas de imitación de sigillata (CIS: 0,29 \% de los fragmentos y $0,33 \%$ del peso) y distintas formas de terra sigillata gris con decoraciones bruñidas — que podrían llegar hasta mediados de la sexta centuria (Juan Tovar, 2012; Raynaud, 1993)—. El grupo más nutrido de cerámicas correspondería a las características cerámicas engobadas lucenses (22\% de los fragmentos y $20 \%$ del peso), producidas desde el cambio de era hasta, por lo menos, mediados de la quinta centuria (Alcorta Irastorza y Bartolomé Abraira, 2012). El segundo grupo más numeroso de producciones correspondería a aquellas realizadas con sistemas de rotación rápida de cocción oxidante, dentro de los conocidos como 
Tabla 2. Cadenas operativas documentadas en el yacimiento de Viladonga

\begin{tabular}{|c|c|c|c|c|c|}
\hline Сто & Descripción & Frag. $\left(n .^{0}\right)$ & Frag. (\%) & Peso (g) & Peso (\%) \\
\hline TSHT & Terra sigillata hispánica tardía & 123 & 5,06 & 811 & 1,56 \\
\hline CIS & $\begin{array}{l}\text { Cerámica imitación de sigillata (CIS). Normalmente con } \\
\text { presencia de barnices color ocre y avellanas con desgrasantes } \\
\text { de pequeño y mediano tamaño de cuarzo y mica plateada. }\end{array}$ & 7 & 0,29 & 173 & 0,33 \\
\hline CCRA & $\begin{array}{l}\text { Cerámica a torno rápido y cocción oxidante con pastas bien } \\
\text { depuradas con desgrasantes de mediano tamaño de cuarzo. }\end{array}$ & 20 & 0,82 & 299 & 0,58 \\
\hline CCRB & $\begin{array}{l}\text { Cerámica a torno rápido y cocciones mixtas (tendente a } \\
\text { oxidantes) de pastas poco depuradas con desgrasantes de } \\
\text { mediano y gran tamaño de cuarzo, mica, mica plateada y } \\
\text { chamota. }\end{array}$ & 879 & 36,15 & 19.149 & 36,92 \\
\hline Engobada & $\begin{array}{l}\text { Producciones a torno rápido de cocciones mixtas, } \\
\text { normalmente oxidante al exterior y reductora al interior. } \\
\text { Presencia de abundantes desgrasantes de mica plateada } \\
\text { de mediano y gran tamaño. }\end{array}$ & 535 & 22,01 & 10.522 & 20,29 \\
\hline TRA/TRC & $\begin{array}{l}\text { Cerámica a torno rápido y cocción reductora, bien depurada } \\
\text { con desgrasantes medianos y pequeños de cuarzo y mica } \\
\text { plateada de buena calidad. }\end{array}$ & 177 & 7,28 & 2.889 & 5,57 \\
\hline TRB & $\begin{array}{l}\text { Cerámica a torno rápido y cocción reductora, escasamente } \\
\text { depurada con desgrasantes de mediano y gran tamaño } \\
\text { (>5 mm) de chamota, cuarzo y mica plateada y dorada. }\end{array}$ & 643 & 26,45 & 15.822 & 30,51 \\
\hline TRB1 & $\begin{array}{l}\text { Cerámica a torno rápido y cocción generalmente mixta } \\
\text { tendente a reductora. Presencia de desgrasantes de gran } \\
\text { tamaño de mica plateada, cuarzo y cuarcita. }\end{array}$ & 24 & 0,99 & 625 & 1,21 \\
\hline \multirow[t]{2}{*}{ TLB } & $\begin{array}{l}\text { Producciones realizadas a torno bajo o a mano, de cocciones } \\
\text { mixtas (con diversas variantes) y escasamente depuradas con } \\
\text { desgrasantes medios y grandes de cuarzo, cuarcita, chamota } \\
\text { y abundante mica plateada. Normalmente asociado a formas } \\
\text { abiertas tipo fuentes. }\end{array}$ & 23 & 0,95 & 1.575 & 3,04 \\
\hline & Total & 2.431 & 100 & 51.865 & 100 \\
\hline
\end{tabular}

ciclos de la cerámica común romana —algunas de las cuales han sido objeto de un reciente estudio (Barbazán Domínguez, et al., 2018)—, tanto en sus variantes depuradas (CCRA: $0,82 \%$ de los fragmentos y $0,58 \%$ del peso) como, sobre todo, en las menos depuradas (CCRB: $36,15 \%$ de los fragmentos y 36,92 \% del peso).

Otro aspecto interesante a destacar del conjunto cerámico de esta fase del yacimiento de Viladonga es la importante presencia de producciones realizadas con sistemas de rotaciones rápidas y de cocción reductora (fig. 2). De ellas se ha distinguido una variante menos depurada (TRB: 26,45\% de los fragmentos y 30,51\% del peso) y otras mejor depuradas y de mayor calidad técnica (TRA y TRC: 7,28 \% de los fragmentos y 5,57 \% del peso). Este tipo de producciones, si bien se pueden documentar con anterioridad 

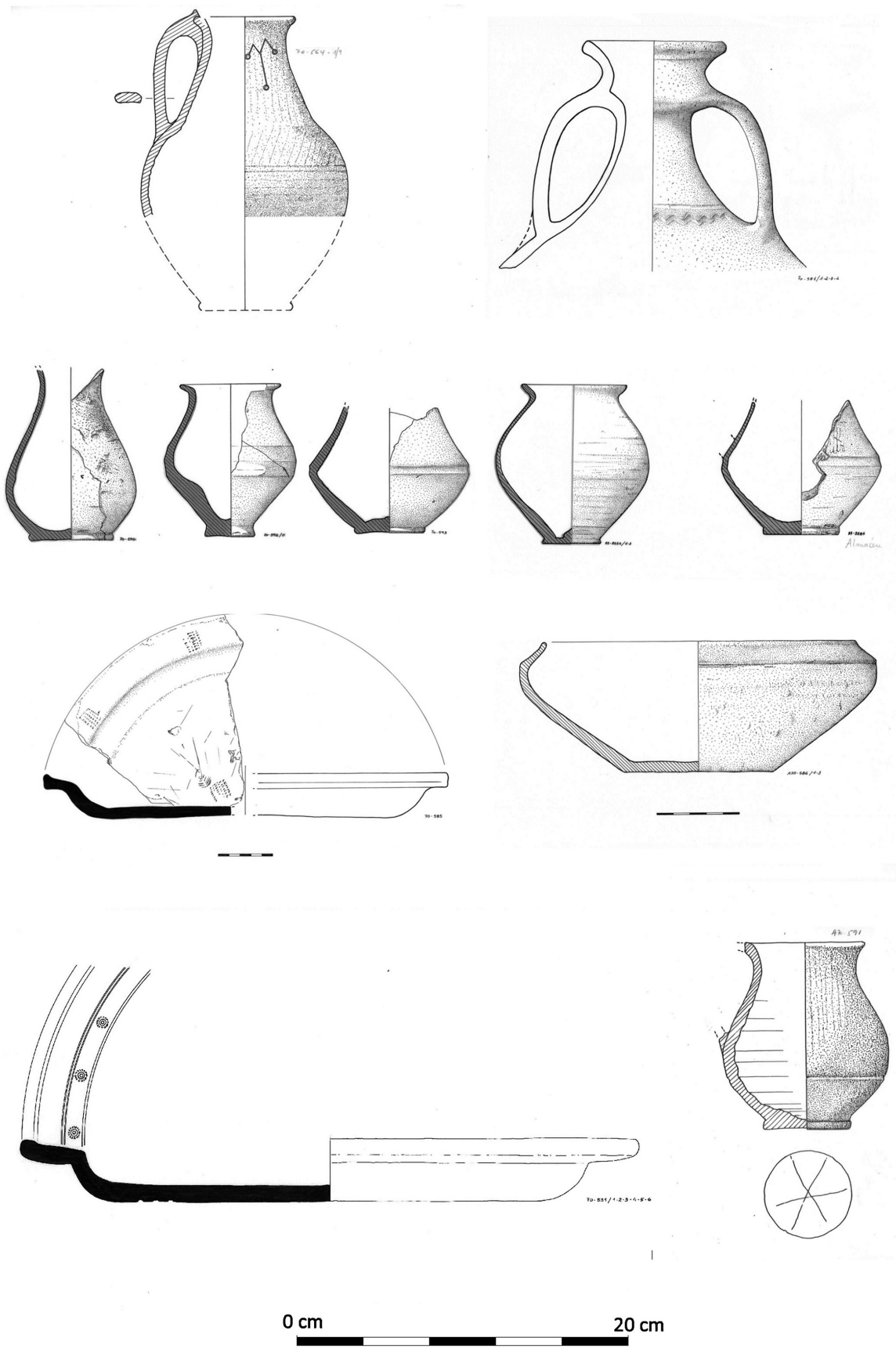

Figura 2. Cerámicas tardías de Viladonga. Dibujos del Museo del Castro de Viladonga. 

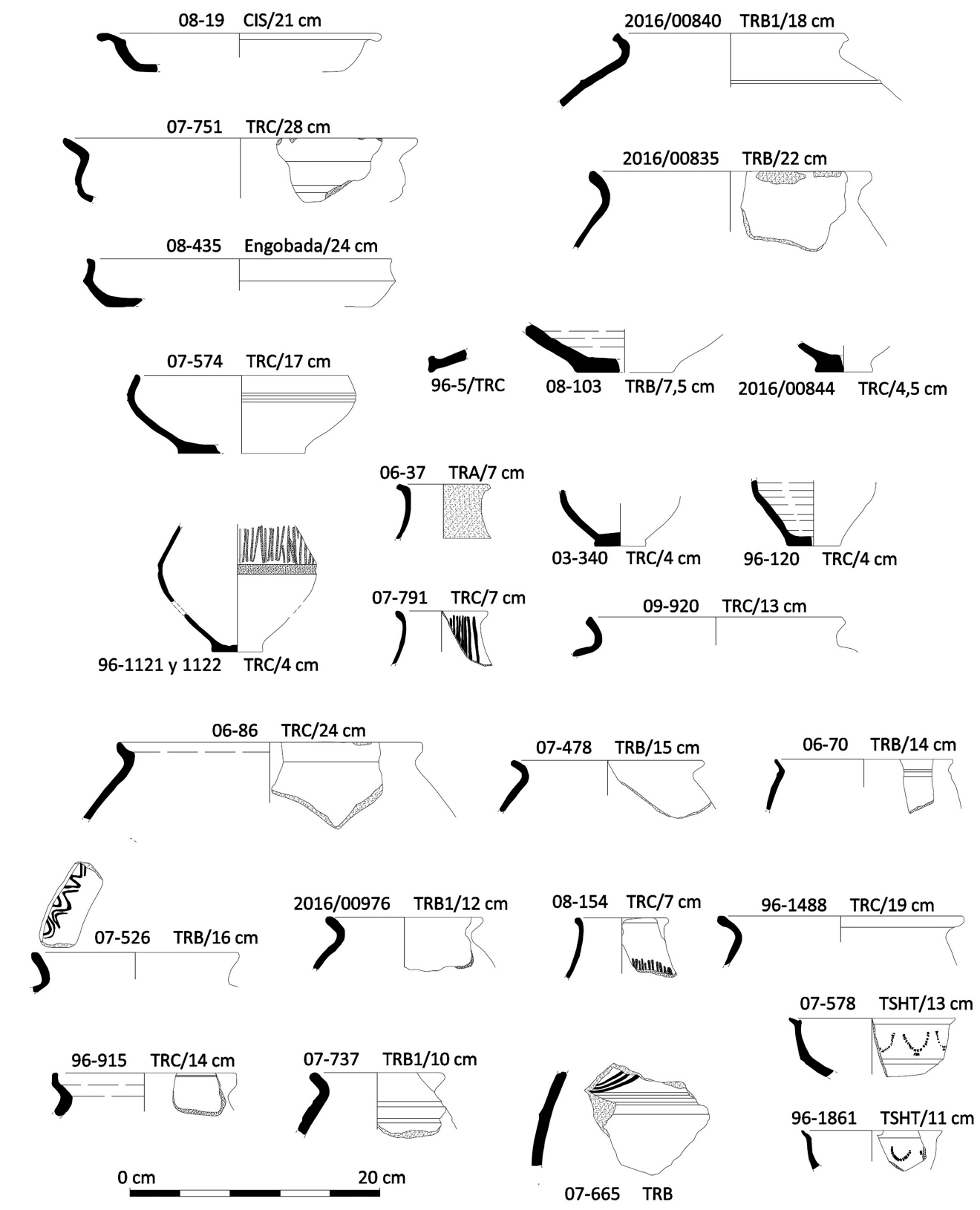

Figura 3. Cerámica de Viladonga (II). Dibujos de los autores. 
asociadas a los ciclos de cerámica común romana, únicamente llegan a alcanzar esta importancia relativa dentro de los conjuntos cerámicos a partir de la segunda mitad de la quinta centuria y ya dentro de la sexta (Fernández Fernández y Bartolomé Abraira, 2016; Vigil-Escalera, 2003).

El conjunto de cerámicas de Viladonga se caracteriza por una gran variedad formal, así como decorativa (véase un estudio completo en Tejerizo García, et al., 2018b) (fig. 3). Así, nos encontramos con prácticamente todo tipo de formas, desde formas abiertas tipo platos — con los característicos platos de grandes dimensiones propios de la quinta centuria (Alcorta Irastorza, 2001) - y fuentes, hasta formas cerradas que incluyen ollas, jarras o botellas. Sin embargo, destaca la mayor incidencia de las formas cerradas $(70,4 \%$ del total documentado) con respecto a las formas abiertas (29,6\%). Cabe mencionar también que una característica singular de los contextos del noroeste en relación a los de la meseta norte es la presencia de pequeños vasitos en producciones engobadas y reductoras de buena calidad técnica, también documentados en Castro Ventosa (Villafranca del Bierzo / Cacabelos), Santomé (Ourense) o, como veremos, Os Castros, en Mondoñedo (Rodríguez González y Xusto Rodríguez, 2019; Tejerizo García y Vigil-Escalera Guirado, 2017). Igualmente, las variedades decorativas son bastante singulares, incluyendo formas muy elaboradas de bruñidos o características incisiones en ondas y líneas horizontales.

\subsection{Os Castros (Mondoñedo, Lugo): finales s. v - s. vi d. n. e.}

Mondoñedo es un municipio localizado en la comarca de A Mariña Central, al norte de la provincia de Lugo. El yacimiento de Os Castros (parroquia de A Couboeira) se encuentra en la cumbre de la colina Pena Capeluda. La geología de esta zona destaca por el macizo de A Toxiza, formado por granitoides biotíticos, con presencia de grandes bloques en superficie, actualmente bastante afectado por la expansión del cultivo de eucaliptos. Su posición en el paisaje le permite el control visual de una amplia zona hacia los cuadrantes norte, este y sur.

A finales de 2017 se realizaron varias zanjas y sondeos con el fin de determinar su potencialidad arqueológica (Vigo García, 2017). Un aspecto relevante de este lugar es la ausencia de vestigios de amurallamiento, lo que alejaría este yacimiento del modelo de asentamiento fortificado, como sería el caso de Viladonga. Varias de estas zanjas y sondeos dieron resultado positivo, localizando diversas estructuras murarias, fosas rehundidas y parte de un cementerio, que fue datado en época medieval. La más interesante para nuestros propósitos es la denominada como "Zanxa Z-06». En esta zanja se localizó una secuencia estratigráfica con varios niveles de relleno y de abandono asociados a los restos de un muro. Este conjunto fue datado por los excavadores entre los siglos IV y vII d. n. e. (Vigo García, 2017: 36), si bien en los niveles más profundos, probablemente de nivelación, también se localizó material prehistórico, así como material moderno en superficie. Aunque no se pudo determinar con seguridad la naturaleza del yacimiento, la ausencia 
Tabla 3. Cadenas operativas documentadas en el yacimiento de 0s Castros de Mondoñedo

\begin{tabular}{|c|c|c|c|c|c|}
\hline сто & Descripción & Frag. $\left(n .{ }^{0}\right)$ & Frag. (\%) & Peso (g) & Peso (\%) \\
\hline PREH & Cerámicas de época prehistórica & 90 & 30,5 & 732 & 16,8 \\
\hline $\mathrm{CIS}$ & $\begin{array}{l}\text { Cerámica imitación de sigillata (CIS). Normalmente con } \\
\text { presencia de barnices color ocre y avellanas con desgrasantes } \\
\text { de pequeño y mediano tamaño de cuarzo y mica plateada. }\end{array}$ & 15 & 5,1 & 286 & 6,5 \\
\hline Engobada & $\begin{array}{l}\text { Producciones a torno rápido de cocciones mixtas, } \\
\text { normalmente oxidante al exterior y reductora al interior. } \\
\text { Presencia de abundantes desgrasantes de mica plateada de } \\
\text { mediano y gran tamaño. Caracterizadas por el engobado a } \\
\text { modo de recubrimiento. }\end{array}$ & 8 & 2,7 & 144 & 3 \\
\hline TRC & $\begin{array}{l}\text { Cerámica a torno rápido y cocción reductora, bien depurada } \\
\text { con desgrasantes medianos y pequeños de cuarzo y mica } \\
\text { plateada de buena calidad. }\end{array}$ & 57 & 19,3 & 697 & 16 \\
\hline TRB & $\begin{array}{l}\text { Cerámica a torno rápido y cocción reductora, escasamente } \\
\text { depurada con desgrasantes de mediano y gran tamaño } \\
\text { (>5 mm) de chamota, cuarzo y mica plateada y dorada. }\end{array}$ & 34 & 11,5 & 1.650 & 37,8 \\
\hline TLATTLB & $\begin{array}{l}\text { Producciones realizadas a torno bajo o a mano, de cocciones } \\
\text { mixtas (con diversas variantes) y escasamente depuradas con } \\
\text { desgrasantes medios y grandes de cuarzo, cuarcita, chamota } \\
\text { y abundante mica plateada. Normalmente asociado a formas } \\
\text { abiertas tipo fuentes. }\end{array}$ & 10 & 3,4 & 480 & 11 \\
\hline $\begin{array}{l}\text { Vidriadas } \\
\text { y modernas }\end{array}$ & Cerámicas de época moderna & 12 & 4 & 171 & 3,9 \\
\hline \multirow[t]{2}{*}{ INDET } & Cerámicas indeterminadas & 69 & 23,4 & 209 & 4,8 \\
\hline & TOTAL & 295 & & 4.369 & \\
\hline
\end{tabular}

de un entorno fortificado parece señalar la presencia de un asentamiento rural en abierto tipo granja o aldea.

En la revisión que pudimos efectuar contabilizamos un total — descontando los fragmentos prehistóricos y modernos- de 124 fragmentos cerámicos con un total de 3,2 kg de peso, entre los cuales se distinguieron hasta ocho CTO distintas, seis de ellas vinculadas con el período aquí estudiado (tabla 3).

Salvando el material residual de época prehistórica (30,5\% de los fragmentos y 16,8 \% del peso), que señalaría una potencial fase de ocupación anterior, y la cerámica moderna proveniente de los estratos superiores ( $4 \%$ de los fragmentos y 3,9 \% del peso), la primera característica a destacar sería la ausencia de TSHT y la documentación de un pequeño conjunto de cerámica de imitación (5,1 \% de los fragmentos y 6,5\% del peso), que nos situaría, a priori, en un momento entre la segunda mitad del siglo v y el siglo vi d. n. e. (Juan Tovar, 2012). Igualmente interesante es tanto la desaparición de las formas y tecnologías tradicionales de los ciclos de cerámicas torneadas de cocción oxidante, como la 
significativa disminución en el conjunto con respecto a Viladonga de la cerámica engobada lucense $(2,7 \%$ de los fragmentos y $3 \%$ del peso). Por el contrario, el grueso de las producciones corresponde a cerámicas realizadas con rotaciones rápidas de cocciones reductoras, tanto en su variedad depurada (TRC: 19,3\% de los fragmentos y $16 \%$ del peso) como en la menos depurada (TRB: $11,5 \%$ de los fragmentos y 36,8 \% del peso). Dicho de otra manera, estas producciones reductoras corresponderían a más del 70 \% del conjunto. Muchas de estas formas, además, aparecen con el característico bruñido exterior de este período, que será común hasta por lo menos la octava centuria (Fernández Fernández y Bartolomé Abraira, 2016). También muy significativo en términos de cadenas operativas sería la aparición de cerámicas realizadas a torno bajo o a mano, con un 3,4% de los fragmentos y un $11 \%$ del peso total.

Formalmente se aprecia una significativa reducción de las formas abiertas (18\%) con respecto a las cerradas $(82 \%)$ en relación al contexto de Viladonga (fig. 4). Sin llegar a desaparecer del registro - y quizá determinado por la extensión y la cantidad de material recuperado-, las formas abiertas tipo cuenco, platos o barreños se reducen muy significativamente, en favor de las formas cerradas tipo ollas y jarras. Entre las primeras, destaca la forma OCM $17-i ?^{2}$, un gran barreño de $38 \mathrm{~cm}$ de diámetro de boca, de cocción reductora y realizada con sistema de rotaciones rápidas, que presenta un perfil ligeramente ondulado y con un labio redondeado y engrosado, ligeramente exvasado. Esta pieza podría ponerse en relación con algunas formas de las cinzentas tardías documentadas en contextos del entorno de Braga (Fernández Fernández, 2014: 78-81), y que se localizan en varios yacimientos del centro y del noroeste peninsular datados en este intervalo entre los siglos V-VI d. n. e. (Tejerizo García, 2016). Igualmente cabría mencionar la fuente engobada OCM 17-2518, de $30 \mathrm{~cm}$ de diámetro de boca y cuerpo bajo de fondo aplanado con el labio plano y borde exvasado, tipo EP4 de Alcorta (Alcorta Irastorza, 2001). En cuanto a las formas cerradas, cabe señalar la presencia de ollas de borde exvasado y redondeado con una ligera carena en el cuello (OCM 17-1682), muy similares a las formas tardías documentadas en el noroeste (Fernández Fernández y Bartolomé Abraira, 2016), así como una pequeña jarrita con asa, dentro de las tecnologías de imitaciones de sigillata (Juan Tovar, 2012). Finalmente, un aspecto que destaca en el registro de Os Castros es la presencia de diversas formas cerradas con pie resaltado (OCM 17-1480, 2518 o 1483). En contextos del centro peninsular estas formas se mantienen hasta los primeros compases de la sexta centuria (Tejerizo García, 2016; Vigil-Escalera, 2013). Dentro de estas, cabe destacar la forma OCM 17-1480, posiblemente correspondiente a un vaso monoansado, por la presencia de un grafitado en el fondo de la pieza. Este tipo de grafitados en el fondo son tremendamente comunes en este período en el noroeste peninsular, y documentados en lugares como Viladonga o Astorga, tratándose posiblemente de una marca de alfarero, tal vez para señalar su finalización (Paz Peralta, 2013; Tejerizo García, et al., 2018b).

2. No se pudo leer la sigla original. 


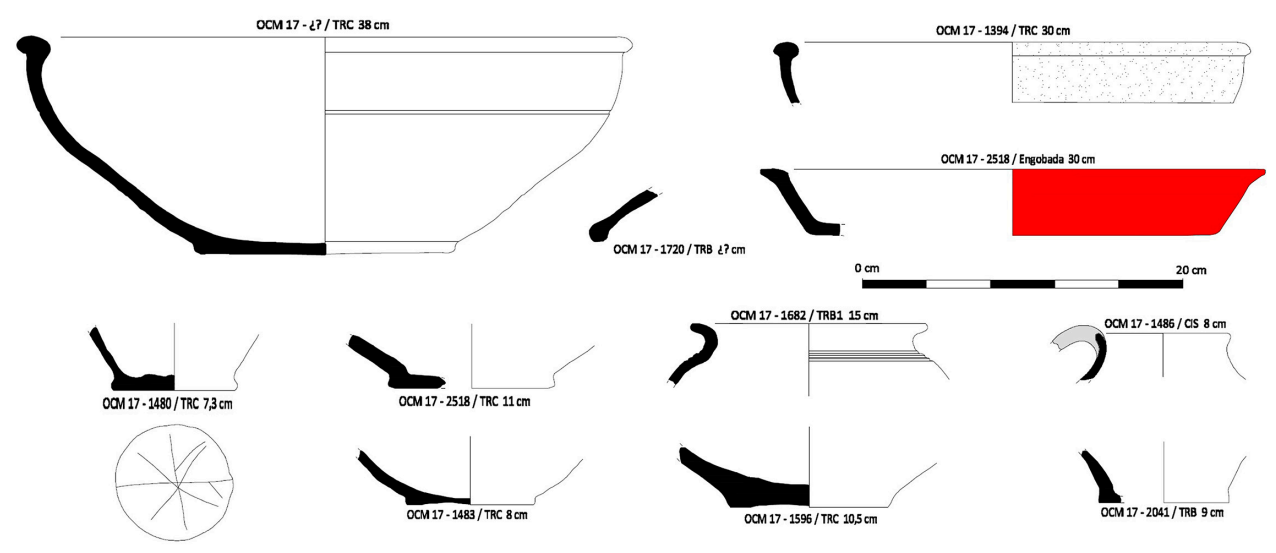

Figura 4. Cerámica de 0s Castros de Mondoñedo. Dibujo de los autores.

En cuanto al aparato decorativo, el repertorio cerámico de Os Castros es bastante similar a lo ya documentado en Viladonga, con una amplia variedad de motivos. El más habitual serían las acanaladuras y líneas incisas horizontales, tanto de forma individual como en grupos de dos o varias líneas que pueden incluso llegar a recubrir gran parte del cuerpo de la pieza (OCM 17-1521). Si bien el bruñido es utilizado de forma generalizada para recubrir y aislar la pieza, en ocasiones se utiliza también de forma decorativa a través de entramados de líneas verticales sobre producciones previamente engobadas (OCM 17-1304), o en retículas de líneas perpendiculares (OCM 17-1593 y 1594).

\subsection{Casanova (Abadín, Lugo): mediados s. vi - s. vII d. n. e.}

El yacimiento de Casanova se sitúa en el límite occidental del actual concello de Abadín (Lugo), en una zona de muy fácil accesibilidad, a escasos metros del trazado del Camiño do Norte a Santiago. En cuanto al subsuelo, se encuentra en la Serie de Vilalba, caracterizada por la presencia de pizarras, esquistos biotíticos, areniscas y gneises anfibolíticos. Fue localizado por primera vez en 1998, cuando se documentaron ocho estructuras de perfil rehundido durante unas obras vinculadas a la instalación de una línea de gas (Morchón Viñas, 2008). Una de estas estructuras fue sondeada, dando como resultado la exhumación de material que fue descrito como «medieval». Como consecuencia de la construcción de una autovía (la actual AP-8), se realizaron hasta dos campañas de excavación en los años 2008 y 2009, con la documentación de hasta 120 estructuras, que incluyeron varios edificios con cimentación de piedra, fondos de cabaña, silos de almacenamiento y fosas indeterminadas (Morchón Viñas, 2008, 2009). El análisis de los materiales exhumados permitió diferenciar dos fases principales: una primera de la II Edad del Hierro — corroborado por la presencia de una fíbula de tipo transmontano en un depósito secundario- y 
Tabla 4. Cadenas operativas documentadas en el yacimiento de Casanova

\begin{tabular}{|c|c|c|c|c|c|}
\hline Сто & Descripción & Frag $\left(n .^{0}\right)$ & Frag (\%) & Peso (gr) & Peso (\%) \\
\hline Preh & Cerámica realizada a mano de la Edad de Hierro. & 70 & 15,2 & 675 & 22,3 \\
\hline Engobada & $\begin{array}{l}\text { Producciones a torno rápido de cocciones mixtas, } \\
\text { normalmente oxidante al exterior y reductora al interior. } \\
\text { Presencia de abundantes desgrasantes de mica plateada de } \\
\text { mediano y gran tamaño. Caracterizadas por el engobado a } \\
\text { modo de recubrimiento. }\end{array}$ & 4 & 1 & 18 & 0,6 \\
\hline TRC & $\begin{array}{l}\text { Cerámica a torno rápido y cocción reductora, semidepurada } \\
\text { con desgrasantes medianos y pequeños de cuarzo y mica } \\
\text { plateada de buena calidad. }\end{array}$ & 9 & 2,2 & 85 & 2,8 \\
\hline TRB & $\begin{array}{l}\text { Cerámica realizada con sistemas de rotaciones rápidas aunque } \\
\text { parece que no uniformes (presencia de ciertas irregularidades } \\
\text { en las marcas de torno) poco depurada con desgrasantes de } \\
\text { pequeño y mediano tamaño de cuarzo, mica plateada y caliza. } \\
\text { Cocciones reductoras con pastas grises al exterior y marrones } \\
\text { oscuras al interior. }\end{array}$ & 81 & 19,5 & 935 & 30,9 \\
\hline TLC & $\begin{array}{l}\text { Cerámica realizada con sistemas de rotaciones lentas, de } \\
\text { características muy similares a la TLB pero con un grado } \\
\text { mayor de depuración y menor tamaño de las inclusiones y } \\
\text { desgrasantes. }\end{array}$ & 10 & 2,4 & 82 & 2,7 \\
\hline TLB & $\begin{array}{l}\text { Cerámica realizada con sistemas de rotaciones lentas y mucha } \\
\text { aportación de mano, poco depurada con desgrasantes de } \\
\text { pequeño y mediano tamaño de cuarzo, mucha mica plateada } \\
\text { de pequeño tamaño. Cocciones mixtas tirando a ambientes } \\
\text { reductores con pastas grises al exterior y marrones al interior. } \\
\text { En ciertas producciones se observa un cierto alisado en el } \\
\text { interior de la pieza. }\end{array}$ & 56 & 13,5 & 509 & 16,8 \\
\hline TLB1 & $\begin{array}{l}\text { Cerámica de características similares a la TLB pero con } \\
\text { cocciones reductoras de pastas grises y negras y presencia de } \\
\text { mica plateada en abundancia de mediano tamaño. }\end{array}$ & 33 & 8 & 192 & 6,3 \\
\hline \multirow[t]{2}{*}{ Indet } & Cerámicas indeterminadas & 150 & 36,1 & 520 & 17,2 \\
\hline & Total & 415 & & 3025 & \\
\hline
\end{tabular}

una segunda adscrita a un período indeterminado «romano-medieval», cuya datación concreta no se especifica.

El material que pudo ser revisado de las estructuras asociadas a la segunda fase del yacimiento, correspondiente en su mayoría a estratigrafías asociadas al abandono del asentamiento, asciende a 415 fragmentos con un peso total de 3,03 kg y un número mínimo de individuos de 89. Se distinguieron hasta 7 cadenas operativas distintas (tabla 4).

En primer lugar, es interesante destacar la total ausencia de sigillata en el contexto de Casanova, así como la mínima representación de cerámica engobada ( 1 \% de los frag- 
mentos y 0,6 \% del peso), que habría que entender entonces como residual, al igual que la cerámica de la Edad del Hierro (15,2 \% de los fragmentos y 22,3\% del peso) presente en las estructuras de esta fase. Hay que resaltar que el final de las producciones engobadas se ha establecido en la quinta centuria y que las formas documentadas pertenecen a piezas típicamente tardoimperiales (sobre todo la forma abierta CTC-08/S2/G-12/205) (Alcorta Irastorza, 2001; Alcorta Irastorza y Bartolomé Abraira, 2012). Por su parte, el grueso de las producciones correspondería a un equilibrio entre las producciones realizadas con sistemas de rotación rápida y cocción reductora (TRB: 19,5 \% de los fragmentos y 30,9\% del peso) y aquellas realizadas con sistemas de rotación lenta y cocción mixta con tendencia a los ambientes reductores (TLB: 13,5\% de los fragmentos y 16,8 \% del peso). Ambas cadenas cuentan con variantes más depuradas, normalmente destinadas a la vajilla de mayor calidad (con rotaciones rápidas, TRC: 2,2 \% de los fragmentos y 2,8 \% del peso; con rotaciones lentas, TLC: $2,4 \%$ de los fragmentos y 2,7 \% del peso). Cabe hacer mención a una variante dentro de las producciones con rotaciones lentas caracterizada por pastas mucho más graníticas y con mucha mica plateada (TLB 1: $8 \%$ de los fragmentos y 6,3\% del peso), que podría, hipotéticamente, corresponder a las denominadas como «cerámicas micáceas de cocina de tradición castrexa» (Fernández Fernández y Bartolomé Abraira, 2016: 96-97). Un aspecto a destacar es que, si bien el bruñido es común en el tratamiento final de las cerámicas, este aparece en una cantidad mucho menor. Las características de este conjunto, puesto en comparación con otros contextos mejor conocidos del centro y norte peninsular, permitirían enmarcarlo en un momento entre finales del siglo vi y toda la séptima centuria, sin descartar, por el momento, que pudiera ya entrar dentro de la octava (Fernández Fernández y Bartolomé Abraira, 2016; Tejerizo García, 2016; Vigil-Escalera, 2003, 2006).

Formalmente cabe destacar un alto grado de simplificación con respecto a los contextos anteriores, estando el conjunto de Casanova mayoritariamente conformado por formas cerradas tipo ollas de cocina o pequeñas jarras, las cuales representarían casi el $95 \%$ de las formas documentadas (fig. 5). Entre estas, el mayor número corresponde a ollas de perfiles en S con el borde exvasado y ligeramente redondeado (CTC-08/52/E-9/1 19, CTC08/G-14/262 o CTC-08/52/D-11/66), con algunas formas que presentan una inflexión muy marcada en el labio (CTC-08/S2/C-10/89 o CTC-08/S2/94). Entre las formas abiertas destacan algunas de tipo cuenco: en concreto, una forma ligeramente carenada de borde recto y redondeado (CTC-08/S2/E-92/02); una segunda forma de cuenco carenado con el borde ligeramente exvasado y con depresión o concavidad para la potencial recepción de tapadera (CTC-08/S2/C-3/185); y una última de características similares a la anterior (CTC-08/S2/A-1/41), salvo por la forma hemisférica y la presencia de una ligera pestaña. Todas estas formas abiertas tienen paralelos en yacimientos tanto del noroeste como del centro peninsular, con cronologías centradas en la segunda mitad de la sexta centuria, pero sobre todo en la séptima (Fernández Fernández y Bartolomé Abraira, 2016; Tejerizo García, 2016; Vigil-Escalera y Strato, 2013).

Por último, cabría destacar dos piezas con formas que llaman la atención. La primera (CTC-08/S2/C-3/106) podría interpretarse como un posible fondo de ánfora, si bien las 


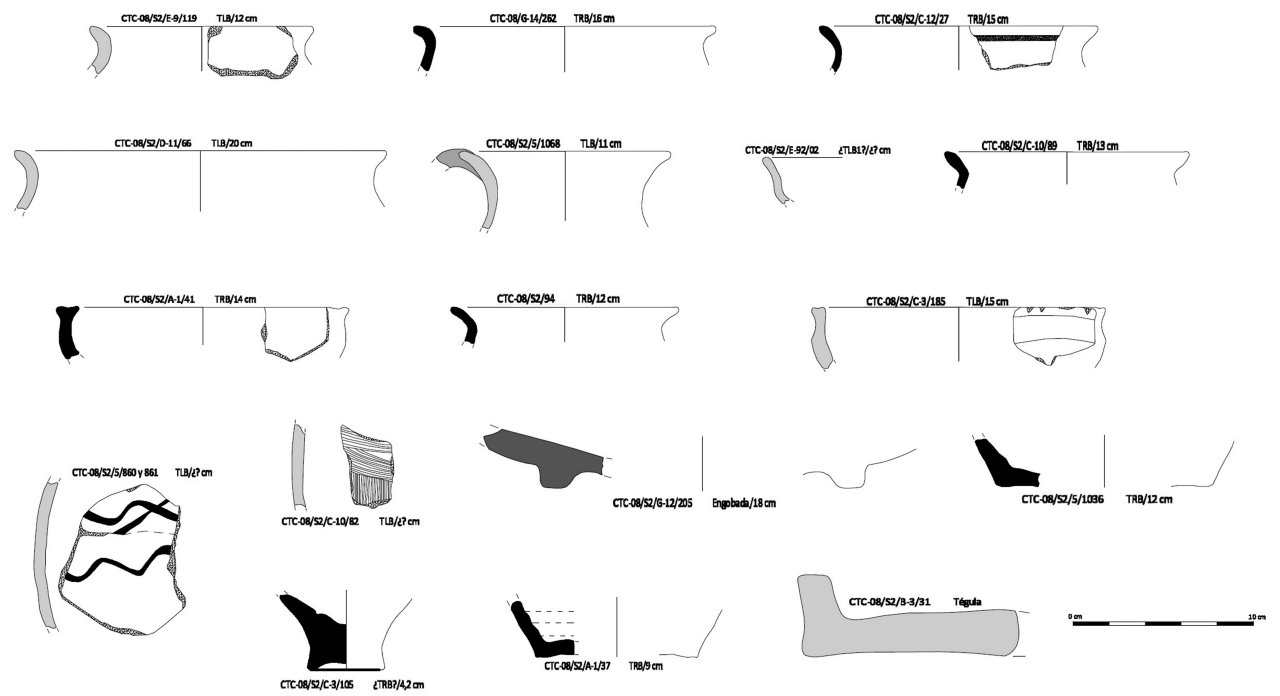

Figura 5. Cerámica de Casanova. Dibujo de los autores.

características de su producción (sobre todo, la cocción reductora) generan ciertas dudas sobre su funcionalidad. Fondos resaltados similares, aunque con mayor desarrollo de las peanas, han sido localizados en contextos tardíos tanto de la ciudad de Lugo como en Vigo y datados en los siglos VI-VII d. n. e. (Fernández Fernández y Bartolomé Abraira, 2016: fig. 2.7.21 y fig. 23.14.26). Más extraña sería otra pieza correspondiente a un potencial pomo de tapadera de cocción oxidante y muy bien depurada (CTC-08/S2/D-10/811), que resalta con respecto al resto de producciones del contexto y cuya naturaleza y datación son dudosas.

$\mathrm{Al}$ igual que con el aparato formal, las decoraciones también se simplifican en el conjunto de Casanova con respecto a los contextos analizados anteriormente. Entre ellas, la más común sería la onda incisa, ya sea individual (CTC-08/S2/C-3/114 o CTC-08/S2/E118-01) o en grupo incluso interseccionando entre ellas (CTC-08/S2/6/850). Por otro lado, se documentan varios fragmentos decorados con líneas incisas tanto horizontales (CTC-08/S2/5/858) como peinados formando grupos (CTC-08/S2/C-10/82). Finalmente, el bruñido también es utilizado como un elemento decorativo, fundamentalmente a través de las líneas verticales (CTC-08/S2/B3/25).

\subsection{A Pousada (Bornais, Santiago de Compostela): s. vII-X d. n. e.}

El sitio de A Pousada (Bornais, Santiago de Compostela) se encuentra en una vaguada que discurre en dirección NO-SE, bajo las tierras de cultivo y a escasos metros del arroyo de Pozo da Valiña, perteneciente a la cuenca del Ulla. El substrato geológico de esta vaguada 
está formado por esquistos ricos en plagioclasa y paragneises. Este yacimiento fue localizado durante los trabajos de Evaluación de Impacto de la autopista Santiago-Ourense y excavado en el año 2001 (Blanco Rotea, et al., 2009). En esta excavación se documentó un conjunto de muros de mampostería, correspondientes a varias fases de construcción de una misma unidad doméstica, y asociados a algunos posibles silos de almacenamiento, el vestigio más antiguo del yacimiento. Esta primera fase fue datada mediante radiocarbono entre finales del siglo vi y el tercer cuarto del vir d. n. e. ${ }^{3}$, mientras que el abandono de esta construcción se situó en un momento en torno al siglo XI (Blanco Rotea, et al., 2009: 114-115). Este yacimiento cuenta, además, con varios estudios cerámicos y análisis arqueométricos que forman una base excepcional para el estudio aquí presentado (Prieto Martínez, 2012; Prieto Martínez, et al., 2018b). El sitio de A Pousada fue interpretado como una granja altomedieval cuya característica más interesante es precisamente su larga duración y su estabilidad (Tejerizo, 2020b).

Dadas las condiciones en las cuales el material se depositó en el Museo Arqueológico e Histórico de A Coruña ${ }^{4}$, no fue posible realizar el análisis por conjuntos estratigráficos completos. Sin embargo, contamos con un estudio previo en el que sí se estudió el material cerámico por fases, el cual ha servido de base para este análisis a partir de la secuenciación estratigráfica realizada originalmente. En este se afirma que el total de fragmentos cerámicos sería de 483 (Prieto Martínez, 2012: 3). En nuestro caso, optamos por analizar una selección de 45 fragmentos (9,3\% del total) de las piezas más representativas de diferentes fases del yacimiento, asociándola al contexto estratigráfico determinado por los informes y estudios originales, como se señala en la tabla 5.

En cuanto a la distinción de las cadenas operativas presentes en el conjunto, el análisis del material cerámico del momento de la excavación distinguió hasta cuatro grupos y 17 subgrupos de pastas, que se reproducen en la tabla 6. Como se puede observar en la tabla, siete son los subgrupos que se pudieron asociar a las producciones altomedievales de A Pousada: 1A (a mano, de pastas grises y compactas/harinosas), 2A (a mano, de pastas negras y compactas/rugosas), 2B (a mano, de pastas negras y compactas finas), 2D (a mano, de pastas negras y compactas/harinosas), 3A (a mano, de pastas rojas y compactas/harinosas), 3B (a mano, de pastas rojas y compactas/rugosas) y 3C (a mano, de pastas rojas y porosas). De esta clasificación y de nuestro análisis cabe destacar varias cuestiones. En primer lugar, que todo el material altomedieval en A Pousada está realizado a mano o con rotaciones muy lentas ${ }^{5}$. Otro elemento interesante es el cambio tecnológico con respecto a los contextos anteriores, en el que el tipo de pastas señalan una menor depuración y cocciones muy irregulares, que serán muy

3. Esta fase fue fechada a partir de una datación correspondiente a una fosa previa a la construcción de la estructura: ROCASOLANO (carbón): 1430 „34 (años BP): 560-663 cal. AD (95,4%), así como de una datación de un agujero

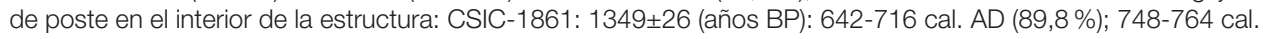
$\mathrm{AD}(5,6 \%)$.

4. En este caso se tomó la decisión de separar cada pieza de su contexto estratigráfico, y la falta de un inventario completo y actualizado impidió poder reconstruir las unidades estratigráficas completas.

5. Dado el grado de fragmentación del material, esta distinción es muy difícil de establecer. 
Tabla 5. Cerámicas analizadas en el yacimiento de A Pousada

\begin{tabular}{llcl}
\hline $\begin{array}{l}\text { Unidad } \\
\text { estratigráfica }\end{array}$ & Tipo UE & $\begin{array}{c}\text { Número de } \\
\text { fragmentos }\end{array}$ & $\begin{array}{l}\text { Fase del yacimiento } \\
\text { (según informe original) }\end{array}$ \\
\hline $65 / 72$ & Depósito de tierra por debajo de un pavimento & 5 & Fase I: VI-VII \\
69 & Relleno fosa circular & 10 & Fase I: VI-VII \\
74 & Depósito de tierra en torno a un muro & 1 & Fase II: VII-VIII \\
82 & Depósito de tierra marrón asociada a construcción & 2 & Fase II: VII-VIII \\
37 & Depósitos asociados a derrumbe de la estructura & 4 & Fase V: XI-XII \\
$66 / 47$ & Depósitos asociados a derrumbe de la estructura & 8 & Fase V: XI-XII \\
39 & Depósitos asociados a derrumbe de la estructura & 4 & Fase V: XI-XII \\
38 & Depósitos asociados a derrumbe de la estructura & 1 & Fase V: XI-XII \\
25 & Escombrera de descartes de teja & 1 & Fase VI: bajomedieval-moderno \\
23 & Escombrera de descartes de teja & 1 & Fase VI: bajomedieval-moderno \\
28 & Escombrera de descartes de teja & 2 & Fase VI: bajomedieval-moderno \\
34 & Fosa & 1 & Fase VI: bajomedieval-moderno \\
67 & Fosa & 1 & Fase VI: bajomedieval-moderno \\
Indet & - & 5 & - \\
\hline
\end{tabular}

comunes a partir de este momento y hasta, por lo menos, el siglo x/xi (Suárez Otero, et al., 1989). Por el contrario, la aparición de producciones de pastas rojas (grupo 3), presentes en la estratigrafía más antigua del yacimiento —dado que se ha documentado tanto en las estructuras previas a la construcción de la unidad doméstica como en los estratos asociados a su ocupación más antigua-, señalaría una importante novedad. Este tipo de producciones han sido recientemente documentadas estratigráficamente en contextos como el Faro de Budiño (O Porriño) (Fernández Pereiro, et al., 2020) y, como veremos, en As Pereiras (denominada TLB2, ver más abajo), y que encuadraríamos en torno a los siglos vII y vIII d. n. e. Esto señalaría un momento entre finales del siglo vII y el siglo viII como el momento de la primera ocupación del sitio, sin descartar que las estructuras previas a la construcción de la unidad doméstica pudieran ser ligeramente anteriores, como bien se ha señalado en las publicaciones al respecto (Blanco Rotea, et al., 2009).

Desde una perspectiva formal se han identificado en el yacimiento un total de 73 recipientes (Blanco Rotea, et al., 2009: 116), que podemos diferenciar por fases a partir de la estratigrafía original (fig. 6). En la fase inicial, correspondiente a las fosas y nivelación del terreno para la construcción de la vivienda entre los siglos VII y vIII, las formas identificadas son ollas y ollitas de cuello corto, borde oblicuo con tendencia al exvasamiento y labio biselado con un ligero engrosamiento en su remate (CAPOU20/041, 043, 044). El recipiente CAPOU20/035 es una ollita de cuello más desarrollado que en los casos anteriores, con un borde ligeramente oblicuo de labio con engrosamiento redondeado. Los fondos cuentan con una ligera concavidad en su superficie exterior y se han identificado 
Tabla 6. Grupos cerámicos diferenciados en A Pousada (Prieto Martínez, 2012)

\begin{tabular}{|c|c|c|c|}
\hline Grupo & Pastas & Morfologías/decoraciones & $\begin{array}{l}\text { Adscripción } \\
\text { cronológica }\end{array}$ \\
\hline $1 \mathrm{~A}$ & $\begin{array}{l}\text { Gris. Compacta harinosa } \\
\text { Monocroma gris. A mano }\end{array}$ & $\begin{array}{l}\text { Compuestas abiertas: jarras, ollas. Lisas. 1-2 litros } \\
\text { Compuestas cerradas: ollas. Lisas. 1-2 litros } \\
\text { No se sabe. Lisas } \\
\text { Simple abierta: lebrillo. Decoración: incisión interna } \\
\text { y cordón digitado externo. } 5 \text { litros }\end{array}$ & Altomedieval \\
\hline $1 \mathrm{~B}$ & Gris. Compacta fina. Monocroma gris. Torno & Compuesta: ollas. Lisas & Moderno \\
\hline $1 \mathrm{C}$ & Gris. Compacta rugosa. Monocroma gris. Torno & No se sabe. Decoración de líneas acanaladas & Moderno \\
\hline $2 \mathrm{~A}$ & $\begin{array}{l}\text { Negra. Compacta rugosa. Monocroma negra. } \\
\text { A mano }\end{array}$ & $\begin{array}{l}\text { Compuesta cerrada: olla. Puede poseer una decoración } \\
\text { a base de incisiones onduladas horizontales } \\
\text { Compuesta cerrada o abierta: jarra }\end{array}$ & $\begin{array}{l}\text { Altomedieval } \\
\text { Bajomedieval } \\
\text { Altomedieval }\end{array}$ \\
\hline $2 \mathrm{~B}$ & $\begin{array}{l}\text { Negra. Compacta fina. Monocroma negra. } \\
\text { A mano }\end{array}$ & $\begin{array}{l}\text { Compuesta cerrada: olla. Lisas } \\
\text { Simple abierta: cuenco. Cordón digitado o incisión }\end{array}$ & $\begin{array}{l}\text { Altomedieval } \\
\text { Bajomedieval } \\
\text { Altomedieval }\end{array}$ \\
\hline $2 \mathrm{C}$ & Negra compacta fina. Monocroma negra. Torno & Compuesta cerrada: olla. Lisa. Perforación en la panza & Bajomedieval \\
\hline $2 \mathrm{D}$ & $\begin{array}{l}\text { Negra. Compacta harinosa. } \\
\text { Monocroma negra. A mano }\end{array}$ & Compuesta. Lisas & Altomedieval \\
\hline $2 \mathrm{E}$ & $\begin{array}{l}\text { Negra. Compacta fina. } \\
\text { Monocroma negra. Torno }\end{array}$ & No se sabe & Moderno \\
\hline $3 \mathrm{~A}$ & $\begin{array}{l}\text { Roja. Compacta harinosa. } \\
\text { Monocroma rojiza. A mano }\end{array}$ & $\begin{array}{l}\text { Compuestas cerradas: ollas. Lisas } \\
\text { Compuestas abiertas: jarra. Lisa } \\
\text { No se sabe. Lisas }\end{array}$ & Altomedieval \\
\hline 3B & $\begin{array}{l}\text { Roja. Compacta rugosa. } \\
\text { Monocroma rojiza. A mano }\end{array}$ & $\begin{array}{l}\text { Compuesta cerrada: olla. Lisas } \\
\text { Compuesta abierta: jarra. Lisa }\end{array}$ & Altomedieval \\
\hline $3 \mathrm{C}$ & $\begin{array}{l}\text { Roja. Porosa media. } \\
\text { Monocroma rojiza. }\end{array}$ & $\begin{array}{l}\text { Simple cerrada: vaso. Una línea acanalada horizontal } \\
\text { en parte inferior }\end{array}$ & Altomedieval \\
\hline & A mano & No se sabe. Lisas & Bajomedieval \\
\hline $4 \mathrm{~A}$ & $\begin{array}{l}\text { Vidriado (amarillo mielado, verdoso mielado, } \\
\text { blanco). Compacta harinosa. Monocroma rosácea. } \\
\text { Torno }\end{array}$ & $\begin{array}{l}\text { Variedad morfológica: simples abiertos (platos) o cerrados } \\
\text { (cuencos) y compuestos abiertos (jarras), en ocasiones con } \\
\text { decoración geométrica pintada. }\end{array}$ & Bajomedieval \\
\hline $4 \mathrm{~B}$ & $\begin{array}{l}\text { Vidriado-barnizado mielado brillante. } \\
\text { Compacto fina. Monocroma gris. Torno }\end{array}$ & $\begin{array}{l}\text { Simple abierta: jarra. Decorada: escena figurativa } \\
\text { (horno de pan). }\end{array}$ & Moderno \\
\hline $4 \mathrm{C}$ & $\begin{array}{l}\text { Vidriado verdoso oscuro. Compacta fina. } \\
\text { Monocroma sepia. Torno }\end{array}$ & Compuesta abierta y cerrada (cuenco). Lisas & Moderno \\
\hline $4 \mathrm{D}$ & $\begin{array}{l}\text { Barnizado marrón brillante. Compacta fina. } \\
\text { Monocroma sepia. Torno }\end{array}$ & Compuesta abierta y cerrada (cuenco). Lisas & Contemporáneo \\
\hline $4 \mathrm{E}$ & $\begin{array}{l}\text { Loza blanca. Compacta fina. Monocroma blanca. } \\
\text { Torno }\end{array}$ & Simple abierta: plato. Lisa & Contemporáneo \\
\hline $4 \mathrm{~F}$ & $\begin{array}{l}\text { Vidriado blanco. Compacta harinosa. Monocroma } \\
\text { rosácea. Torno }\end{array}$ & Simple abierta: plato. Lisa & \\
\hline
\end{tabular}


1. FOSAS PREVIAS Y NIVELACIÓN PARA CONSTRUCCIÓN CASA (Finales s. VII/s.VIII)

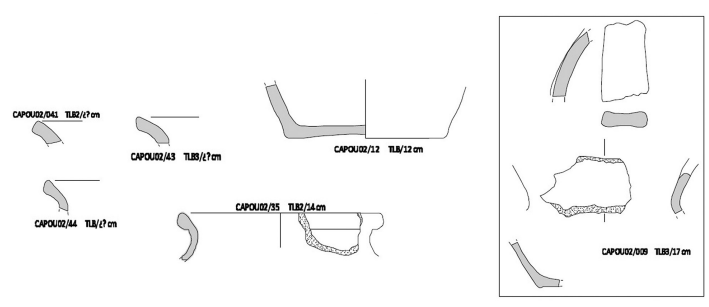

2. OCUPACIÓN UNIDAD DOMÉSTICA (S. VIII-X/XI)
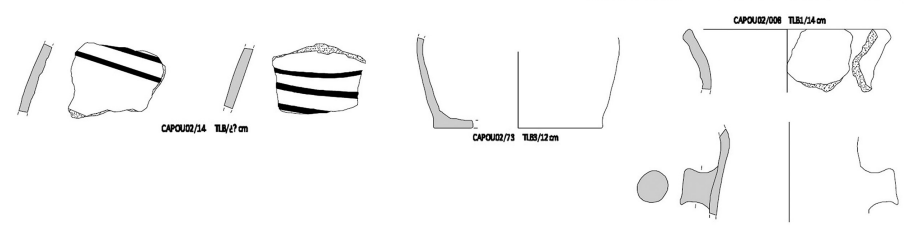

3. ABANDONO UNIDAD DOMÉSTICA (S. $X / X I)$
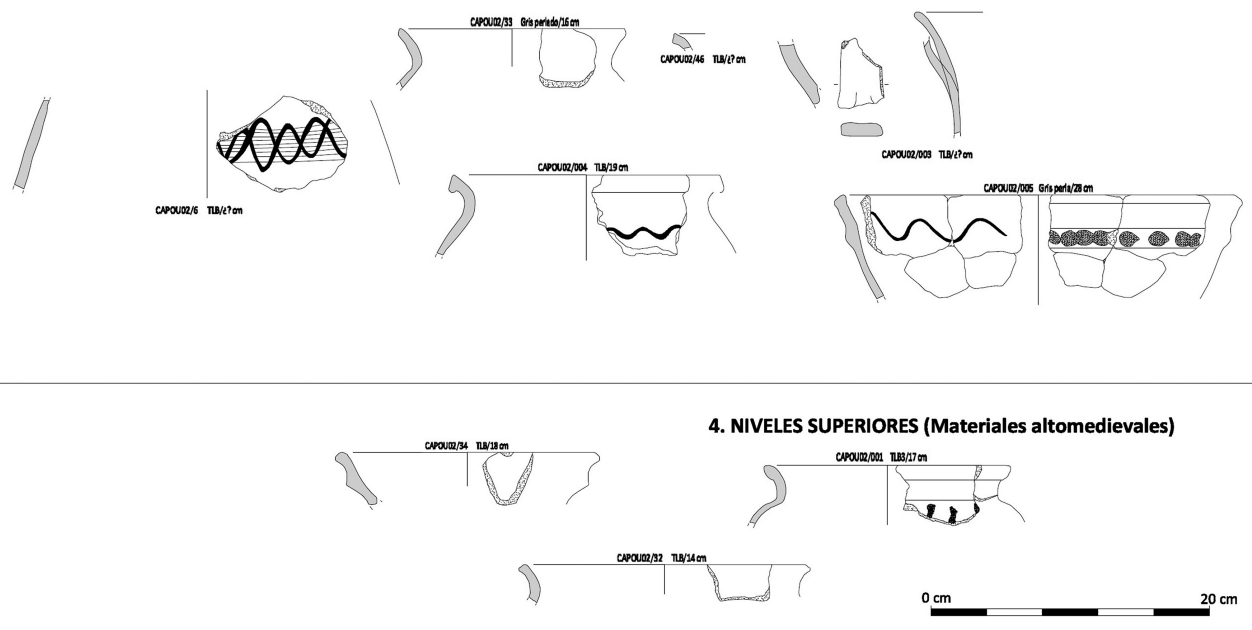

Figura 6. Cerámicas de A Pousada. Dibujo de los autores a partir de Prieto, 2012.

asas, lo cual podría indicar la presencia de jarras, aunque no se han podido relacionar con ningún borde.

A nivel decorativo esta fase presenta una llamativa ausencia de elementos, salvo en piezas localizadas en niveles superficiales que coincidirían en pastas con las propias de esta fase, como por ejemplo la olla CAPOU20/001, con digitaciones verticales en su panza. Otros recipientes tipificados con cautela como altomedievales, al ser localizados en niveles superficiales, son los CAPOU20/032-034. El primero se trata de una ollita de borde 
ligeramente oblicuo, labio biselado con una mínima protopestaña ${ }^{6}$ y línea rehundida en su exterior. El segundo se corresponde con una forma desconocida, un posible lebrillo o cuenco de borde oblicuo y labio engrosado con una carena exterior en su punto medio.

Para la siguiente fase de ocupación, que se data entre los siglos VIII y x/XI d. n. e., contamos únicamente con una forma reconocible pero desconocida en el conjunto galaico (CAPOU20/008). Se trata de un recipiente abierto, de borde ligeramente oblicuo y labio biselado, de $14 \mathrm{~cm}$ de diámetro, cuyas panzas cuentan con un mamelón, posiblemente para facilitar su colgado. Dado que no se documentó un perfil completo para esta pieza y el escaso tamaño de su borde asociado, podemos encontrarnos ante un formato de tipo ollita o jarra. Con respecto al aparato decorativo de esta fase, el único motivo identificado son las incisiones o acanaladuras sobre panzas, no asociadas a formas concretas. En estos fragmentos, se documentan dos líneas incisas en uno y tres en otro, con tendencia al paralelismo, pero sin que este sea perfecto.

Ya en la última fase de interés para nuestro estudio, la correspondiente al abandono de la unidad doméstica, realizado muy probablemente entre los siglos x y xI, seguimos contando con ollas de borde oblicuo o ligeramente oblicuo, como en el caso de los recipientes CAPOU20/033-046, con labio biselado. Pero también se identifican ligeras modificaciones en los bordes, las cuales podrían ser diagnósticas del cambio cronológico, como en el caso del CAPOU20/004, una olla de borde oblicuo con labio biselado y con una protopestaña más desarrollada que en la fase anterior. En esta fase se cuenta también con jarras de morfología no identificada, pero reconocidas por el perfil de sus asas y panzas (CAPOU20/003). La novedad de esta fase es la documentación de un lebrillo (CAPOU20/005), una forma abierta de paredes oblicuas y borde biselado apuntado hacia el interior. Cuenta con una rica decoración, con un cordón digitado perimetral exterior en el que se puede reconocer la impronta de las fibras del trapo empleado por el alfarero o alfarera. En el interior, una línea incisa en zigzag complementa el conjunto. Estas incisiones son identificadas en otras piezas de esta fase con líneas simples o una mayor concentración y densidad de las mismas en algunos casos.

\subsection{As Pereiras (Amoeiro, Ourense): s. viII-X d. n. e.}

Este yacimiento se encuentra en Trasalba, concello de Amoeiro, y muy próximo a su linde con el de Ourense. Situado en el límite sur de una pequeña altillanura con una altitud media de 400 msnm. El substrato geológico está formado por granitos y leucogranitos de dos micas, pero también se ha constatado en esta zona la presencia muy limitada de esquistos, cuarcitas, paragneises y metavulcanitas ácidas. Fue excavado en 1998 en el contexto de un control de la construcción de la Red de Gasificación de Galicia y catalogado como

6. Preferimos usar el término protopestaña, puesto que hemos detectado que este elemento de los bordes de olla sobresale más del perfil de la pieza, convirtiéndose en una verdadera pestaña a medida que avanza la Edad Media (Suárez Otero, et al., 1989). 
«romano-medieval» debido a las dificultades para la identificación de los materiales (Aboal Fernández y Cobas Fernández, 1999). La excavación de un sondeo en el sitio deparó la documentación de un muro asociado a algunas estructuras rehundidas. Al igual que en el sitio de Casanova, la aparición de material prehistórico permitió diferenciar varias fases de ocupación, la segunda de las cuales fue aproximada por los excavadores a los siglos v y viI d. n. e. a partir de la presencia de un singular broche de cinturón de placa calada (Aboal Fernández y Cobas Fernández, 1999: 27). Cabe destacar que, en las cercanías del yacimiento de As Pereiras, a kilómetro y medio hacia el nordeste, se localizó otro yacimiento, denominado A Mora, cuyo material tiene una clara cronología tardorromana, con la presencia de abundantes sigillatas (Aboal Fernández y Cobas Fernández, 1999: 28). La revisión de la estratigrafía y del material asociado nos ha permitido concluir que el contexto contaría, al igual que en el caso de Casanova, con dos fases principales: una centrada en la Prehistoria Reciente (posiblemente del Hierro I) y otra fase de época altomedieval.

El material que pudo ser revisado de las estructuras asociadas a la segunda fase del yacimiento asciende a 2.133 fragmentos, con un peso total de $25,8 \mathrm{~kg}$, en 14 unidades estratigráficas distintas y con un número mínimo de individuos de 148, entre los cuales se distinguieron hasta 13 CTO distintas (tabla 7):

En cuanto a las cadenas operativas documentadas en As Pereiras, cabe destacar un alto grado de residualidad de materiales prehistóricos (75\% de los fragmentos y 79, 1 \% del peso total), pero también las escasas cantidades de cerámicas de contextos posiblemente de época romana (terra sigillata: 0,1 \% de los fragmentos y 0,1 \% del peso; CCRB: 0,2 \% de los fragmentos y 0,3\% del peso; CCRC: $0,3 \%$ de los fragmentos y 0,3\% del peso). En lo que respecta al material prehistórico, su alta presencia en el conjunto se explicaría por la existencia de un momento de ocupación previo en ese mismo entorno, cuyos materiales se incorporarían a la estratigrafía a partir de una nivelación del terreno para la construcción de las estructuras medievales, aspecto que ya se ha señalado para los sitios de Viladonga y Casanova. En cuanto al escaso material de época romana temprana, es muy probable que provenga del cercano yacimiento de A Mora, aportado durante los primeros momentos de ocupación de este contexto. También es probable, aunque no seguro, que otras producciones realizadas con sistemas de rotaciones rápidas se puedan considerar residuales dentro del contexto de As Pereiras, como son las producciones tipo TRB (0,9\% de los fragmentos y $0,8 \%$ del peso), TRB $1(0,4 \%$ de los fragmentos y $0,6 \%$ del peso) y TRC $(0,5 \%$ de los fragmentos y $0,3 \%$ del peso).

En cualquier caso, y eliminando la potencial residualidad cerámica, el grueso de las producciones de la fase altomedieval de As Pereiras y las que están presentes en las estratigrafías contemporáneas a su ocupación se caracterizan por la fabricación a mano o con sistemas de rotaciones muy lentas, con cocciones muy irregulares y pastas de colores grises o pardos (TLB: 4,1 \% de los fragmentos y 3,2 \% del peso), o de colores más blanquecinos (TLB 1: 3,1 \% de los fragmentos y 2,5\% del peso). Otras dos producciones que destacan en el conjunto son aquellas realizadas a mano o con sistemas de rotación lenta de cocciones tendentes a oxidantes y con pastas de color rojo, con una variante menos depurada 
Tabla 7. Cadenas operativas documentadas en el yacimiento de As Pereiras

\begin{tabular}{|c|c|c|c|c|c|}
\hline сто & Descripción & Frag $\left(n^{0}\right)$ & Frag (\%) & Peso (gr) & Peso (\%) \\
\hline Preh & Cerámicas a mano de época prehistórica & 1600 & 75 & 20459 & 79,1 \\
\hline $\mathrm{TSH} / \mathrm{TH}$ & Terra sigillata genérica & 2 & 0,1 & 4 & 0,1 \\
\hline CCRB & $\begin{array}{l}\text { Cerámica realizada con sistemas de rotaciones rápidas de cocciones } \\
\text { reductoras con pastas de color gris o mixta poco depuradas. }\end{array}$ & 5 & 0,2 & 67 & 0,3 \\
\hline CCRC & $\begin{array}{l}\text { Cerámica realizada con sistemas de rotaciones rápidas de cocciones } \\
\text { oxidantes y pastas semidepuradas de colores mixtos }\end{array}$ & 6 & 0,3 & 82 & 0,3 \\
\hline TRB & $\begin{array}{l}\text { Cerámica realizada con sistemas de rotaciones rápidas de cocciones } \\
\text { reductoras y pastas grises semidepuradas. }\end{array}$ & 19 & 0,9 & 202 & 0,8 \\
\hline TRB1 & $\begin{array}{l}\text { Cerámica realizada con sistemas de rotaciones rápidas de cocciones } \\
\text { muy irregulares de pastas muy graníticas con mucho desgrasante de } \\
\text { mica plateada y cuarzo, de colores pardos y paredes muy gruesas. }\end{array}$ & 8 & 0,4 & 150 & 0,6 \\
\hline TRC & $\begin{array}{l}\text { Cerámica realizada con sistemas de rotaciones rápidas de cocciones } \\
\text { reductoras y pastas blanquecinas o ligeramente anaranjadas } \\
\text { semidepuradas. }\end{array}$ & 10 & 0,5 & 68 & 0,3 \\
\hline TLB & $\begin{array}{l}\text { Producción a mano o con sistemas de rotaciones muy lentas poco } \\
\text { depurada con desgrasantes de mediano tamaño de mica plateada, } \\
\text { algo de mica dorada y cuarzo. Cocciones muy irregulares tendentes } \\
\text { a reductoras pero con mucha variación de colores. Pastas de colores } \\
\text { grises y pardos. Paredes gruesas (0,5-0,8 mm.). }\end{array}$ & 88 & 4,1 & 833 & 3,2 \\
\hline TLB1 & $\begin{array}{l}\text { Producción a mano o con sistemas de rotaciones muy lentas poco } \\
\text { depuradas similar a TLB pero de pastas de colores blanquecinos } 0 \\
\text { pardos. }\end{array}$ & 67 & 3,1 & 640 & 2,5 \\
\hline TLB2 & $\begin{array}{l}\text { Variante de la TLB pero con cocciones más irregulares al interior y } \\
\text { exteriores tendentes a oxidantes al exterior con pastas de color rojo. }\end{array}$ & 95 & 4,5 & 980 & 3,8 \\
\hline TLB3 & $\begin{array}{l}\text { Cerámica realizada con sistemas de rotación lenta, poco depurada } \\
\text { y desgrasantes de mediano tamaño con mucha mica plateada, mica } \\
\text { dorada y cuarzo. Cocciones irregulares tendentes a la oxidación al } \\
\text { exterior que dejan pastas de color rojo muy característico al exterior. }\end{array}$ & 33 & 1,5 & 527 & 2 \\
\hline TLC & $\begin{array}{l}\text { Cerámica a mano o con sistemas de rotación lenta, semidepurada, } \\
\text { de desgrasantes de pequeño tamaño y mucha mica plateada y cuarzo. } \\
\text { Cocciones irregulares pero tendentes a oxidantes, que dejan pastas } \\
\text { de colores pardos y anaranjados. Superficies exteriores e interiores } \\
\text { alisados. }\end{array}$ & 83 & 3,9 & 801 & 3,1 \\
\hline TLC1 & $\begin{array}{l}\text { Variante de la TLC pero con cocciones netamente reductoras con } \\
\text { pastas de colores grises y negruzcos. }\end{array}$ & 34 & 1,6 & 303 & 1,2 \\
\hline \multirow[t]{2}{*}{ INDET } & Cerámicas indeterminadas & 82 & 3,8 & 736 & 2,8 \\
\hline & Total & 2133 & & 25857 & \\
\hline
\end{tabular}


(TLB2: 4,5\% de los fragmentos y 3,8 \% del peso; muy similar al grupo 3 definido para A Pousada), muy similares a las descritas para A Pousada, y otra mejor depurada con superficies exteriores alisadas de color rojo muy característico (TLB 3: 1,5\% de los fragmentos y $2 \%$ del peso; también presente en el conjunto de A Pousada). Finalmente, cabe distinguir una variante algo mejor depurada, si bien dentro de las producciones a mano o con sistemas de rotación lenta de cocciones tendentes a oxidantes (TLC: 3,9 \% de los fragmentos y 3,1 \% del peso) o netamente reductoras (TLC1: 1,6 \% de los fragmentos y 1,2\% del peso).

A nivel formal nos encontramos con ollas, ollitas, jarras, una posible fuente y una posible mielera (fig. 7). En cuanto a las ollas, todas presentan cuellos poco estrangulados y bordes ligeramente oblicuos, con matices entre las piezas, que muestran mayor o menor inclinación en su borde, como por ejemplo la PERl/1422 y la PERl/510, con una inclinación más próxima a la verticalidad. La primera, con un labio simple ligeramente redondeado, y la segunda, con labio simple. El resto de ollas cuentan con bordes de labio biselado o con una sutil protopestaña. En el caso de las ollitas, contamos con el ejemplar PERl/256, de unos $6 \mathrm{~cm}$ de diámetro, cuello poco estrangulado y que, lamentablemente, no conserva el remate de su borde. No se ha podido relacionar ningún fondo con su correspondiente borde, pero el yacimiento de As Pereiras cuenta con la peculiaridad de poseer por lo menos dos fondos con reborde perimetral; este tipo de fondos se ha vinculado a lebrillos, en yacimientos contemporáneos de la zona de Santiago como A Pousada o Padrón (Alonso Toucido, 2015: 247), en Ouvigo (Os Blancos) o en São Gens, en el Alto Mondego portugués (Tente, et al., 2014: 129), pero en As Pereiras no se identifica ningún borde de lebrillo, pudiendo tratarse de ollas con reborde en su fondo.

Para las jarras contamos con el ejemplo del PER1/1264, un recipiente de cuello esbelto y borde simple, del que desconocemos su diámetro. Con respecto a la mielera, se trata de un recipiente del cual sólo contamos con fragmentos de la parte superior de su panza, con un saliente perimetral, pero no nivelado, con una disposición ondulante. Generalmente en las mieleras, o potes meleiros en portugués, estos salientes están nivelados para incorporar agua y evitar así la aproximación de hormigas y otros insectos (Morais, 2006).

Desde un punto de vista decorativo, en As Pereiras se documentan líneas incisas en zigzag, presentes en la ollita PER1/256, o, de forma destacada, cepillados verticales en el exterior de sus panzas. Esta característica decorativa ha sido identificada en recipientes indeterminados y en una olla, al igual que en el conjunto cerámico localizado en Cova Eirós, Triacastela, y datado en torno a la décima centuria (César Vila, et al., 2018: 87).

A falta de dataciones radiocarbónicas que permitan cerrar la horquilla, podría datarse el conjunto de As Pereiras, de forma aproximada, entre el siglo VII/VIII y el siglo IX/x d. n. e. Por su parte, el broche utilizado para datar originalmente el contexto, de clara adscripción tardorromana, apareció en un nivel superior junto con material residual, por lo que se debería considerar que se encuentra en posición secundaria. La hipótesis más lógica sería pensar que vino aportado al contexto desde el próximo yacimiento de A Mora, cuyo material encaja con la cronología del propio broche (Aboal Fernández y Cobas Fernández, 1999: 28). 

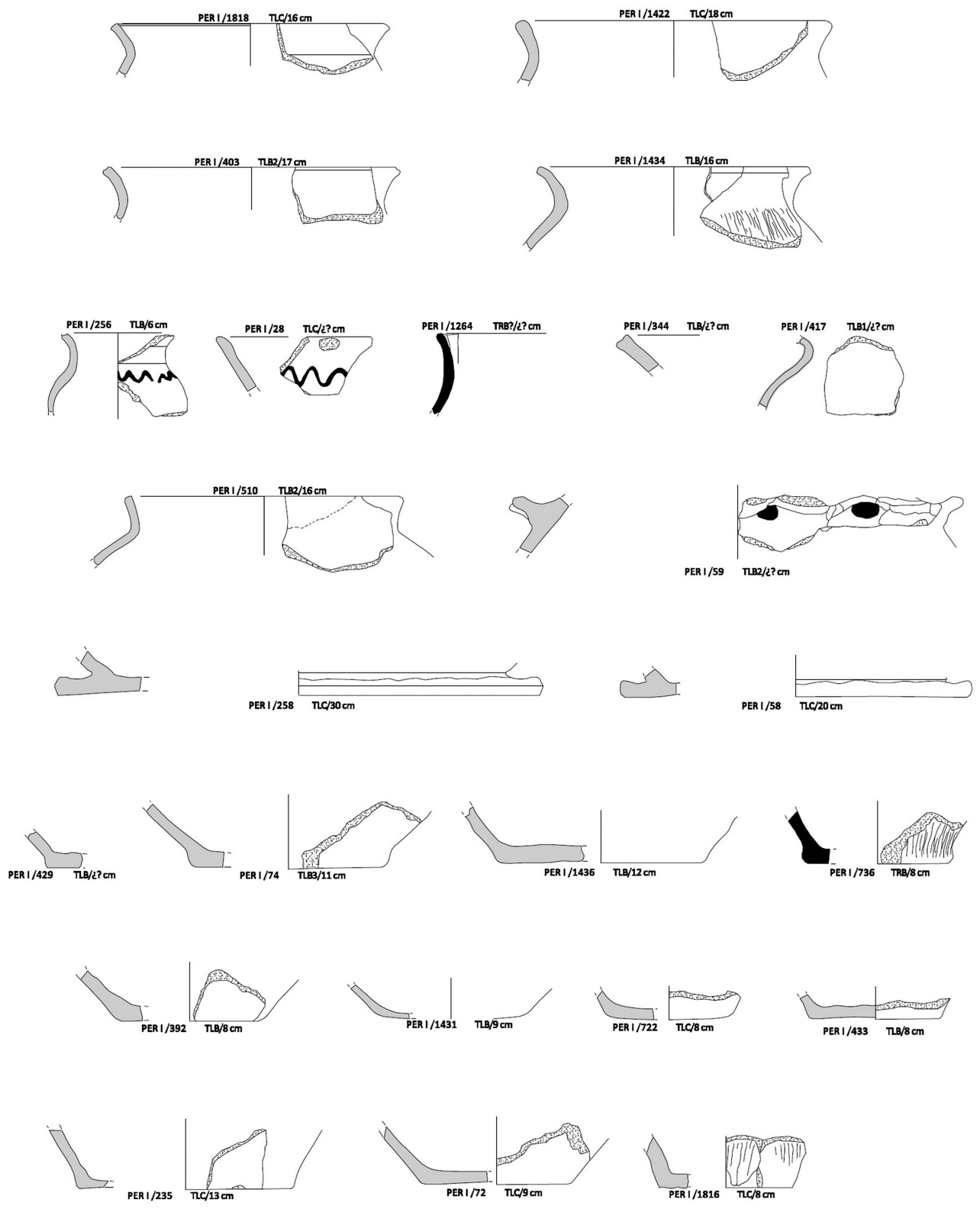

$0 \mathrm{~cm}$ $15 \mathrm{~cm}$

Figura 7. Cerámica de As Pereiras. Dibujo de los autores a partir de Aboal y Cobas, 1999. 


\section{Algunos apuntes sobre la producción cerámica en los contextos rurales del interior de Galicia entre el siglo $\mathrm{v}$ y el $\mathrm{x} / \mathrm{xI}$ d. $\mathrm{n}$. e.}

Una vez expuestos los datos, sintetizaremos en este apartado las principales características y transformaciones de los contextos cerámicos analizados entre los siglos v y x/xI d. n. e. Comenzamos reafirmando que, dados los objetivos y el espacio de este trabajo, esta discusión se plantea como una primera aportación que deberá ser corroborada y contrastada en futuros trabajos.

La quinta centuria, y sobre todo su segunda mitad, supone un momento de grandes transformaciones en lo que a producción cerámica se refiere. Como ya mostraron diversos autores, a lo largo de este siglo convergen una muy significativa cantidad de producciones cerámicas, derivadas de las transformaciones del Imperio romano y sus provincias hacia una progresiva regionalización y reducción de las escalas en las redes de producción, distribución y consumo (Vigil-Escalera, 2003). El caso de Viladonga es un buen ejemplo en este sentido, dada la importante cantidad de producciones que se documentan en el yacimiento, así como en su ocupación ya desde momentos anteriores, que permiten observar los cambios producidos en este momento de la quinta centuria, y que incluyen diversas producciones de sigillata y sus imitaciones, así como una muestra amplia de cerámicas comunes (Barbazán Domínguez, et al., 2018). En particular, cabe destacar la ausencia en los contextos de TSHT a partir de mediados de la quinta centuria, demostrado por su total inexistencia en los sitios de Os Castros y Casanova, aspecto que ya ha sido puesto de relieve en otros estudios (Tejerizo García, $2016 ; 2020 a$ ). Igualmente diverso es el repertorio formal y decorativo de las producciones de Viladonga, que incluye prácticamente toda la variabilidad posible tanto en formas abiertas como en formas cerradas.

Tanto el tipo de producciones como el repertorio formal y decorativo se reducen progresivamente a medida que se cruza la frontera de la sexta centuria, como mostrarían los contextos de Os Castros y de Casanova — si bien teniendo en cuenta lo reducido de las muestras (fig. 8) - El elemento más significativo en este período se observa a nivel de las cadenas operativas, con un crecimiento muy significativo de las producciones con cocciones reductoras, que prácticamente representan toda la producción cerámica de estos contextos. En el caso del noroeste, esto vendría a confirmar lo que ya afirmaran A. Fernández y R. Bartolomé de que «en algún momento de mediados del siglo v se produce, de forma progresiva, un cambio en la producción de estas cerámicas, cuyo máximo exponente será el paso de las cocciones mayoritariamente oxidantes a las cocciones reductoras y de los acabados con tonos rojizos a los grises» (Fernández Fernández y Bartolomé Abraira, 2016: 74). Junto a esta preeminencia de las producciones reductoras, también se destaca la extensión de la técnica del bruñido como forma de impermeabilización exterior, aspecto que también ha sido detectado de forma generalizada en los contextos de la mese- 

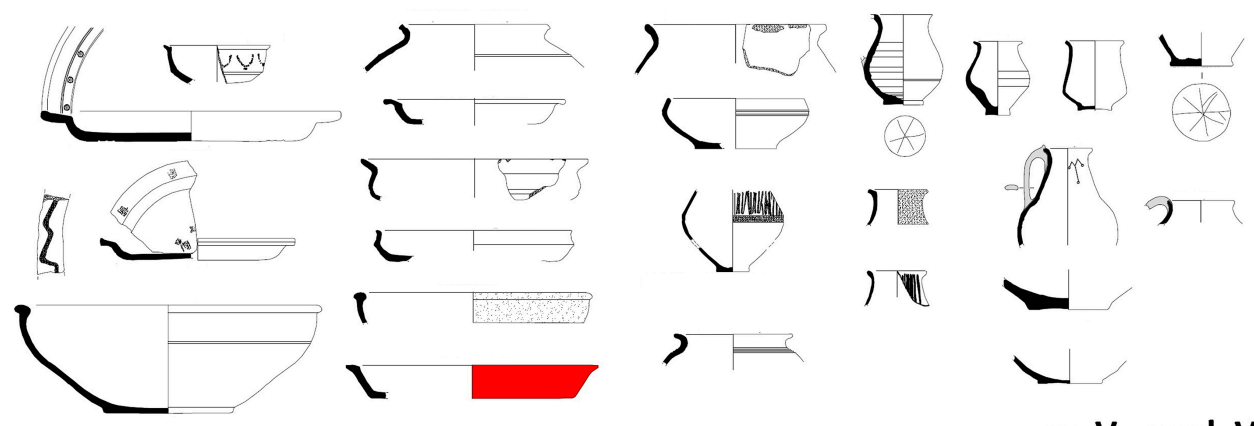

ss. V - med. VI

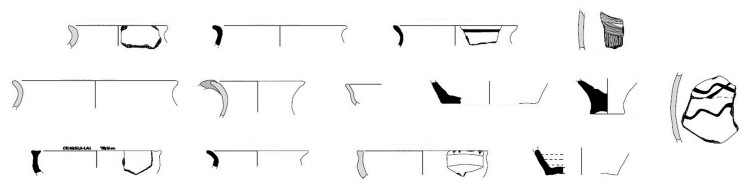

ss. med VI - VII

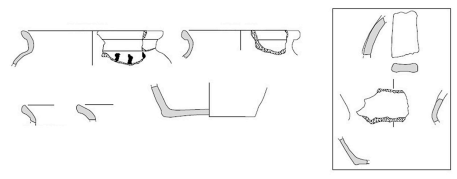

ss. VII - VIII
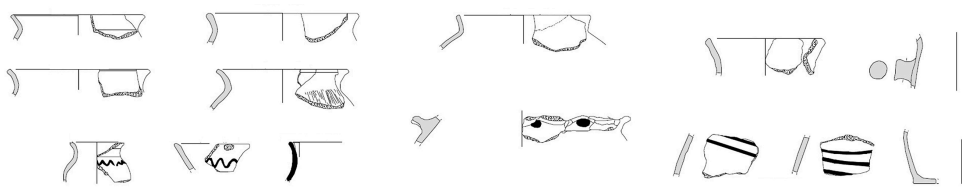

$\sqrt{\min (\sin )}$

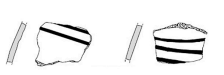

12

19

ss. VIII/IX - X
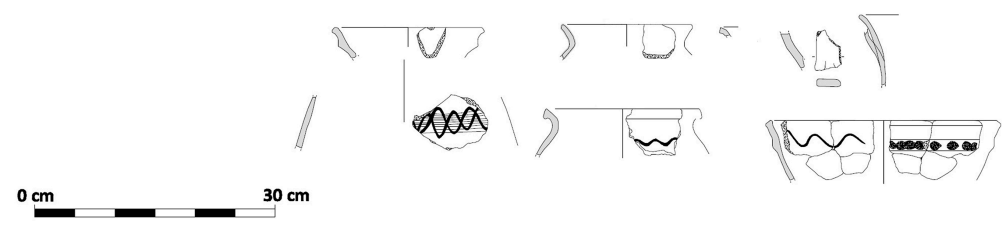

ss. $X / X I-X I I$

Figura 8. Propuesta de secuencia cerámica a partir de los yacimientos analizados. 
ta norte peninsular (Tejerizo García, 2016, 2020a). Esto implica también la desaparición de otras producciones, con especial mención a la cerámica engobada, que ya aparece como residual en Os Castros y totalmente ausente en Casanova, lo que confirmaría la hipótesis de que el fin de su producción se produciría durante mediados o el tercer cuarto de la quinta centuria. Es en este momento período cuando la regionalización cerámica comienza a ser muy significativa y los repertorios, sobre todo los de la cerámica común, reducen sus escalas de producción, distribución y consumo (Tejerizo García, 2020a). Sin embargo, aunque esta regionalización se intensifica en estos momentos, es interesante resaltar que los grandes procesos descritos, como la mayor preeminencia de la cerámica reductora a partir de la sexta centuria, son comunes con otros espacios peninsulares, incluido el noroeste peninsular.

Estas tendencias parecen agudizarse a medida que se avanza hacia la séptima centuria. Varias son las diferencias relevantes detectadas entre los contextos de Os Castros y Casanova que marcarían esta transición. En primer lugar, la reducción de los tipos de producciones detectadas, sobre todo aquellas vinculadas con las últimas imitaciones de sigillata, caso de las TSBT (terra sigillata bracarense tardía), derivadas de DSP (dérivée de sigillée paléochrétienne) o similares, todavía mínimamente presentes en Os Castros pero totalmente ausentes en Casanova. En segundo lugar, la reducción de la variedad formal y la desaparición de algunas formas que habían sido comunes en repertorios anteriores, como son los vasos monoansados con potencial marcaje en su base o los grandes cuencos y barreños. Por otro lado, la aparición y extensión de algunas formas, con especial relevancia de los cuencos carenados o las ollas globulares con bordes exvasados y redondeados. En último lugar, la reducción en los aparatos decorativos, basados casi exclusivamente en las ondas incisas y en la aparición de unos peinados muy particulares que, en algunos casos, se mantendrán en siglos posteriores, aunque con diferencias significativas de unos contextos a otros.

Si bien sería difícil de fijar el momento exacto, entre la séptima y la octava centuria se produce una transformación especialmente significativa en la producción cerámica del noroeste peninsular que afecta a prácticamente todos los elementos de sus cadenas operativas, con especial incidencia en la menor depuración de las pastas, la creciente irregularidad en las cocciones, la reducción del aparato decorativo y el uso cada vez más extendido de las rotaciones lentas. También es difícil por el momento definir con exactitud las características específicas de las producciones de la octava y de la novena centuria, si bien existen algunas particularidades específicas. Cabe destacar, en primer lugar, la preeminencia de las producciones realizadas a mano o con sistemas de rotación lenta en los conjuntos. Esta es una tendencia que ya se manifestaba de forma significativa en los conjuntos de la séptima centuria, pero que ahora se hace extensible a prácticamente todo el repertorio cerámico. Igualmente, se detecta una importante reducción del aparato formal, reducido a unas pocas formas, fundamentalmente cerradas, y a la aparición de elementos que van a ser característicos de las producciones medievales en el noroeste, como son las pestañas, cuyo inicio hemos podido detectar en este período y que hemos 
caracterizado como "protopestañas», para diferenciarlas de las aristadas pestañas características del mundo bajomedieval. Es interesante, en este sentido, la comparación con yacimientos excavados en el entorno, como el de Cova Eirós. Lamentablemente, las cerámicas de Cova Eirós no cuentan con una secuencia estratigráfica clara, sino que se encuentran en unidades estratigráficas «removidas» (César Vila, et al., 2018: 87). Entre las cerámicas de esta cavidad se observan características similares a las de las documentadas en los yacimientos objeto del presente estudio, destacando las denominadas ollas de borde corto y ollas de borde engrosado, con cepillados verticales, pastas negras groseras y relativo grosor de las panzas, las cuales podrían remitirse a momentos previos a los siglos X-XI, marcados por las dataciones absolutas. Puesto que sería en la Plena Edad Media cuando los bordes biselados y de protopestaña — también presentes en el registro de este yacimiento, pero con una cadena operativa diferenciada de la anteriormente mencionada- se hagan habituales en Galicia.

Con respecto a los bordes de ollas, constatamos la presencia de bordes cortos ligeramente oblicuos que, posteriormente, en la Plena Edad Media, acentuarán su inclinación, para ya en la Baja Edad Media constatarse una gran presencia de bordes horizontales, convirtiendo este nivel de ángulo de inclinación del borde de las ollas en un potencial indicador cronológico del período (Alonso Toucido, 2015: 244). Aunque las formas cerradas son prácticamente hegemónicas, también se documentan formas abiertas muy características, con especial relevancia de los barreños de base en disco o lebrillos de reborde perimetral, que aparecen de forma novedosa en los conjuntos. Será en este momento cuando buena parte del servicio de mesa desaparezca, siendo sustituidas las formas abiertas de tipo fuentes, platos y cuencos, por ollas y barreños. Este hecho no tiene por qué implicar necesariamente una pérdida de estos tipos, sino el cambio en su material de fabricación: la cerámica por la madera. Como así ha sido constatado en varios casos, como el del Banco de España, en Santiago de Compostela, con fuentes y platos en madera, de época altomedieval (Del Río Canedo, et al., 2016). Además, se detecta la introducción de algunos elementos de decoración muy característicos que se mantendrán en el tiempo, caso de las digitaciones, mientras que otros, como los peinados o las ondas incisas, se extienden y se hacen más complejos.

Una de las características que resaltábamos del apartado historiográfico es que el grueso de las publicaciones de cerámica medieval en Galicia se centraba en el período pleno y bajomedieval, mucho mejor conocido. De esta manera, podemos establecer con cierta seguridad en el siglo XI/XII d. n. e. un punto de llegada en nuestro recorrido, dado que los principales elementos que caracterizarán a los conjuntos cerámicos a partir de este momento, mejor conocidos, están ausentes en los contextos analizados, como serían las características jarras trilobuladas, las producciones "gris perlada», las ollas y jarras con pestañas desarrolladas o las cerámicas pintadas (Alonso Toucido, et al., 2014; César Vila, et al., 2010; Suárez Otero, 1993; Suárez Otero, et al., 1989), comunes a partir del siglo XII/XIII d. n. e. 


\section{Conclusiones y perspectivas de trabajo}

Como se comentaba al inicio de este trabajo, partíamos de una situación de vacío historiográfico sobre las secuencias cerámicas en el mundo rural del noroeste peninsular que cubrieran el período entre el fin del Imperio romano y la Alta Edad Media. Un vacío que lastraba algunos problemas analíticos sobre el registro arqueológico, sometido a distintos determinismos historiográficos que forzaban las interpretaciones de los contextos, dificultando así la posibilidad de historiar con cierto grado de precisión este período. El desarrollo de la arqueología en Galicia en los últimos años está permitiendo abrir nuevas vías de trabajo, entre las que se encuentran, por ejemplo, la reinterpretación de las transformaciones de los patrones de poblamiento, el comercio tras el fin del Imperio romano de Occidente o, como abordamos en el presente trabajo, las producciones cerámicas en el mundo rural. El análisis llevado a cabo sobre una selección de yacimientos excavados recientemente nos ha permitido proponer una secuenciación cerámica completa del período.

Por otra parte, esta secuenciación, en tanto que análisis diacrónico, nos ha permitido también abordar algunos de los aspectos más relevantes de las transformaciones en la producción cerámica, los cuales, a su vez, señalan significativos cambios en las estructuras políticas, sociales y económicas de las sociedades rurales del período entre el fin del Imperio romano y la Alta Edad Media. Así, y en línea con lo ya observado por otros autores que han abordado este período en el noroeste peninsular, se observa una reducción progresiva de las escalas políticas y sociales hacia una mayor regionalización de las relaciones sociales, que incluye la contracción de las redes de producción y distribución de producciones como la cerámica, así como, en contraste, un mayor peso del mundo rural en la configuración de los paisajes altomedievales en el noroeste peninsular (Sánchez Pardo, 2010; Wickham, 2005). Estos son sólo algunos de los aspectos que, a través de la cerámica, como uno de los mejores indicadores arqueológicos de los que se disponen, podrán abordarse con mayor precisión y rigurosidad en el futuro. Hipótesis que aquí construimos a través de una propuesta que se presenta como un primer paso que deberá ser contrastado y corroborado en el futuro a través de su puesta en comparación con otros registros, tanto antiguos como nuevos. Si bien queda mucho por investigar y analizar, los análisis cerámicos de la última década, para los que este trabajo espera ser una aportación útil, están abriendo grandes posibilidades para profundizar en la enorme complejidad que caracterizó a estos entornos en un período que, poco a poco, vamos conociendo mejor.

\section{Agradecimientos}

Este trabajo ha sido realizado en el marco del Proyecto "Agencia campesina y complejidad sociopolítica en el noroeste de la Península Ibérica en época medieval» (Ministerio de Economía, Industria y Competitividad, AEI/FEDER UE HUM2016-76094-C4-2-R), del 
Grupo de Investigación en Arqueología Medieval, Patrimonialización y Paisajes Culturales / Erdi Aroko Arkeologia, Ondaregintza eta Kultur Paisaiak Ikerketa Taldea (Gobierno Vasco, IT1 193-19) y del Grupo de Estudios Rurales (Unidad Asociada UPV/EHU-CSIC). Queremos agradecer a la profesora Pilar Prieto Martínez sus indicaciones sobre el yacimiento de A Pousada. Igualmente, agradecemos a los evaluadores externos las indicaciones para la mejora del trabajo. Cualquier error en este sentido es responsabilidad exclusiva de los autores.

\section{Bibliografía}

ABOAL FERNÁNDEZ, R. y COBAS FERNÁNDEZ, I., 1999, La arqueología en la gasificación de Galicia 10: sondeos en el yacimiento romanomedieval de As Pereiras, TAPA 13, 1-65.

ACUÑA CASTROVIEJO, F., CASAL GARCÍA, R. y RODRÍGUEZ RESINO, Á., 2012, XXV años de arqueología medieval en Galicia (1985-2010), Boletín de Arqueología Medieval 16, 121 -140.

ACUÑA FERNÁNDEZ, P., COSTA IGLESIAS, A., DE LA PEÑA SANTOS, A. Y RODRÍGUEZ CASAL, A., 1976, Prospecciones arqueológicas en la "Torre de Meira» (Moaña, Pontevedra), Boletín Auriense VI, 183-205.

ADROHER AUROUX, A. M., CARRERAS MONFORT, C., DE ALMEIDA, R., FERNÁNDEZ FERNÁNDEZ, A., MOLINA VIDAL, J. y VIEGAS, C., 2016, Registro para la cuantificación de cerámica arqueológica: estado de la cuestión y una nueva propuesta. Protocolo de Sevilla (PRCS/14), Zephyrus LXXVIII, 87-110.

ALCORTA IRASTORZA, E. J., 2001, Lucus Augusti (vol. II): cerámica común de cocina y mesa hallada en las excavaciones de la ciudad, Fundación Pedro Barrié de la Maza, A Coruña.

ALCORTA IRASTORZA, E. J. y BARTOLOMÉ ABRAIRA, R., 2012, Muestras de cerámica engobada romana de producción local de Lucus Augusti (Lugo), en D. BERNAL CASASOLA y A. RIBERA I LACOMBA (eds.), Cerámicas hispanorromanas II. Producciones regionales, Universidad de Cádiz, Cádiz, 699-724.
ALONSO TOUCIDO, F., 2015, Estudio preliminar de la cerámica del área de Santiago de Compostela en época plenomedieval, en R. MARTÍNEZ PEÑíN y G. CAVERO DOMÍNGUEZ (eds.), Evolución de los espacios urbanos y sus territorios en el Noroeste de la Península Ibérica, Ediciones El Forastero, León, 239-252.

ALONSO TOUCIDO, F., PRIETO MARTÍNEZ, M. P. y RODRÍGUEZ RESINO, Á., 2014, Cerámica en silos. Contextos medievais e modernos na rúa do Franco n. ${ }^{\circ}$ 31. Santiago de Compostela, Gallaecia 32, $215-248$.

ARIAS VILAS, F., DURÁN FUENTES, M. C., BASTOS BERNÁRDEZ, D. Y VARELA ARIAS, E., 2013, Museo do Castro de Viladonga (Castro de Rei, Lugo), Xunta de Galicia, Santiago de Compostela.

BARBAZÁN DOMÍNGUEZ, S., RAMIL REGO, E. y LOZANO HERMIDA, H., 2018, La evolución cronológica del Castro de Viladonga (Castro de Rei, Lugo) a través del estudio de su cerámica común romana, Boletín del Seminario de Estudios de Arte y Arqueología LXXXIV, 168-214.

BLANCO ROTEA, R., PRIETO MARTÍNEZ, M. P., BALLESTEROS, P. y LÓPEZ GONZÁLEZ, L. F., 2009, Capítulo 11. El despoblado de A Pousada: la formación de una aldea rural en la Alta Edad Media, en M. P. PRIETO MARTÍNEZ y F. CRIADO BOADO (eds.), Reconstruyendo la historia de la comarca del Ulla-Deza (Galicia, España). Escenarios arqueológicos del pasado, Consejo Superior de Investigaciones Científicas, Santiago, 111-120. 
BONILLA RODRÍGUEZ, A. y CÉSAR VILA, M., 2005, Excavación arqueológica en área en el solar de la antigua capilla y lazareto medieval de S. Lázaro (Santiago de Compostela, A Coruña), Gallaecia 24, 219-242.

CARAMÉS MOREIRA, V., CASTRO LORENZO, M. L. y SUÁREZ OTERO, J., 2006, Cerámicas de lujo en la Galicia del siglo xv, en F. SINGUL (ed.), Os Capitulos da Irmandade: peregrinación y conflicto social en la Galicia del siglo XV, Xunta de Galicia, Santiago de Compostela, 200-211.

CÉSAR VILA, M. y BONILLA RODRÍGUEZ, A., 2003, Estudio de los materiales cerámicos del "Castelo da Lúa» (Rianxo, A Coruña), Gallaecia 22, 297-367.

CÉSAR VILA, M., BONILLA RODRÍGUEZ, A. y LÓPEZ PÉREZ, M. C., 2010, Aportaciones al conocimiento de la cerámica producida en la última fase de la Edad Media en Galicia, en R. MARTÍNEZ PEÑín (ed.), Metodología de análisis aplicada a los estudios de cerámica tardoantigua y medieval de la Península Ibérica, Universidad de León, León, 145-160.

CÉSAR VILA, M., DE LOMBERA HERMIDA, A., FÁBREGAS VALCARCE, R. y RODRÍGUEZ ÁLVAREZ, X. P., 2018, Estudio de la cerámica medieval de Cova Eirós (Triacastela, Lugo), Cuadernos de Estudios Gallegos LXV, 73-105.

COLL CONESA, J. (ed.), 2011, Manual de cerámica medieval y moderna, Museo Arqueológico Regional, Alcalá de Henares.

CRIADO BOADO, F., MARTÍNEZ LÓPEZ, M. del C. y AMADO REINO, X., 1998, La arqueología en la gasificación de Galicia 1: programa de control y corrección de impacto arqueológico, Universidade de Santiago de Compostela, Santiago de Compostela.

CHAMOSO LAMAS, M., 1951, Excavaciones en Torres de Oeste (Catoira-Pontevedra), Cuadernos de Estudios Gallegos 6, 283-284.

CHAMOSO LAMAS, M., 1972-1974, Noticia sobre la importancia arqueológica de Iria Flavia (Padrón-La Coruña), Archivo Español de Arqueología 45-47, 125-137.
DE LA PEÑA SANTOS, A., 1985, El castillo de Soutomaior: informe arqueológico, El Museo de Pontevedra XXXIX, 143-158.

DE MAN, A. y TENTE, C., 2014, Estudos de cerâmica medieval. O norte e centro de Portugal, séculos IX a XII, Instituto de Estudos Medievais, Lisboa.

DEL RÍO CANEDO, V., FERREIRO DIZ, O. y ALONSO TOUCIDO, F., 2016, Ajuar doméstico en las mesas compostelanas de época medieval: madera y cerámica como caso de estudio, en R. CORDEIRO MACENLLE y A. VÁZQUEZ MARTÍNEZ (eds.), Estudo de Arqueoloxía, Prehistoria e Historia Antiga: achegas dos novos investigadores, Andavira Editora, 425-438.

FARIÑA BUSTO, F., 1975, Contribución ao estudo da cerámica medieval en Galicia, Cuadernos de Estudios Gallegos 29, 51-64.

FARIÑA BUSTO, F. y SUÁREZ OTERO, J., 1988, Arqueoloxía medieval en Galicia: unha aproximación, Trabalhos de Antropologia e Etnologia XXVIII/3-4, 49-77.

FERNÁNDEZ FERNÁNDEZ, A., 2014, El comercio tardoantiguo (ss. IV-VII) en el Noroeste peninsular a través del registro cerámico de la ría de Vigo, Roman and Late Antique Mediterranean Pottery 5, Archaeopress, Oxford.

FERNÁNDEZ FERNÁNDEZ, A. y BARTOLOMÉ ABRAIRA, R., 2016, Cerámicas tardoantiguas en el Noroeste de la Península (Galicia y norte de Portugal): entre la importación y el artesanado local/ regional (ss. v-VII), en J. A. QUIRÓS CASTILLO y A. VIGIL-ESCALERA (eds.), La cerámica de la Alta Edad Media en el cuadrante noroeste de la Península Ibérica (siglos $V$-X): sistemas de producción, mecanismos de distribución y patrones de consumo, Universidad del País Vasco, Bilbao, 69-111.

GRASSI, F. y QUIRÓS CASTILLO, J. A. (eds.), 2018, Arqueometría de los materiales cerámicos de época medieval en España, Universidad del País Vasco, Bilbao.

GUTIÉRREZ GONZÁLEZ, J. A. y BOHIGAS ROLDÁN, R. (eds.), 1989, La cerámica medieval en el norte y noroeste de la Península Ibérica: aproximación a su estudio, Universidad de León, León. 
JUAN TOVAR, L. C., 2012, Las cerámicas imitación de sigillata en el occidente de la Península Ibérica durante el siglo v d. C., en D. BERNAL CASASOLA y A. RIBERA I LACOMBA (eds.), Cerámicas hispanorromanas II. Producciones regionales, Universidad de Cádiz, Cádiz, 97-129.

KRAMER, C., 1985, Ceramic Ethnoarchaeology, Annual Review of Anthropology 14, 77-102.

LEMONNIER, P., 1992, Elements for an Anthropology of Technology, University of Michigan, Míchigan.

MARTÍN VISO, I., FUENTES MELGAR, P., SASTRE BLANCO, J. C. y CATALÁN RAMOS, R., 2018, Cerámicas altomedievales en Hispania y su entorno (s. v-vIII d. C.), Glyphos, Madrid.

MARTíNEZ CASAL, J. R., 2006, A cerámica medieval da fortaleza de A Rocha Forte. Contribución ao seu estudo, Gallaecia 25, 187-225.

MARTÍNEZ PEÑín, R., 2013, Los estudios de cerámica medieval en el noroeste de la Península: Galicia y Norte de Portugal, Interconexões. Revista de Ciências Sociais 1, 33-60.

MORAIS, R., 2006, Potes meleiros e colmeias em cerâmica: uma tradição milenar, Saguntum 38, 149-161.

MORCHÓN VIÑAS, J., 2008, Informe valorativo 1. Excavación arqueológica en área en el yacimiento de Casanova, GA27001016 Castromaior, S. Xoán de Castromaior (Abadín, Lugo), Informe inédito depositado en el Museo de Viladonga.

MORCHÓN VIÑAS, J., 2009, Informe valorativo 2. Excavación arqueológica en área en el yacimiento de Casanova, GA27001016 Castromaior, S. Xoán de Castromaior (Abadín, Lugo), Informe inédito depositado en el Museo de Viladonga.

ORTON, C., TYERS, P. y VINCE, A., 1997, La cerámica en arqueología, Ed. Crítica, Barcelona.

PAZ PERALTA, J. Á., 2013, La vajilla de cerámica hispánica tardía gris y naranja en Asturica Augusta (Astorga, León). Conjunto C, Ex Officina Hispana. Cuadernos de la SECAH 1, La Ergástula, Madrid, 217-256.
PRIETO MARTíNEZ, M. P., 2012, Estudio de la cultura material del yacimiento de A Pousada, Memoria técnica inédita.

PRIETO MARTÍNEZ, M. P., ALONSO TOUCIDO, F., LANTES SUÁREZ, Ó., ACUÑA CASTROVIEJO, F. y CASAL GARCÍA, R., 2018a, Los azulejos de A Rocha Branca (Padrón, A Coruña): un estudio arqueométrico, Gallaecia 37, 127-142.

PRIETO MARTÍNEZ, M. P., ALONSO TOUCIDO, F., LANTES SUÁREZ, Ó., RODRÍGUEZ PAZ, A., BLANCO ROTEA, R. Y GARCÍA QUINTELA, M., 2019, El depósito ritual de jarritas de la Basílica de Augas Santas (Allariz, Ourense): un ejemplo de sincretismo religioso en la Edad Media, Archeologia Medievale XLVI, 287-313.

PRIETO MARTÍNEZ, M. P., LANTES SUÁREZ, Ó. y ALONSO TOUCIDO, F., 2018b, Contribución de la arqueometría a la caracterización de la cerámica medieval en Galicia, en J. A. QUIRÓs CASTILLO y F. GRASSI (eds.), Arqueometría de los materiales cerámicos de época medieval en España, Universidad del País Vasco, Bilbao, 79-110.

PRIETO MARTÍNEZ, M. P., LANTES SUÁREZ, Ó., VÁZQUEZ LIZ, P. y MARTÍNEZ CORTIZAS, A., 2010, La cerámica de dos túmulos de Roza das Aveas (Outeiro de Rei, Lugo): un estudio diacrónico del estilo y la composición, Boletín del Seminario de Estudios de Arte y Arqueología LXXVI, 27-62.

QUIRÓS CASTILLO, J. A., 2018, The future of Medieval Archaeology in Spain. Reflections and proposals, en J. A. QUIRÓS CASTILLO (ed.), Treinta años de Arqueología Medieval en España, Archaeopress, Oxford, 1-20.

RAYNAUD, C., 1993, Céramique Estampée grise et orangée dite "dérivée de sigillée paléochrétienne», Lattara 6, 410-418.

RIU RIU, M., 1977, La arqueología medieval en España, en M. de BOÜARD (ed.), Manual de arqueología medieval, Teide Base, Barcelona, 375-490.

RODRÍGUEZ COLMENERO, A., COVADONGA CARREÑO, M., UNZUETA, M. A., SOBRADO, J. L., ALCORTA, E., VARELA, T. y VALEA, Á., 1985, 
Excavaciones arqueológicas en Ouvigo, Blancos (Orense) (campañas 1977-1981), Noticiario Arqueológico Hispánico 24, 265-388.

RODRÍGUEZ GONZÁLEZ, X. y XUSTO RODRÍGUEZ, M., 2019, Santomé. Conxunto arqueolóxico natural, Xunta de Galicia, Ourense.

SÁNCHEZ PARDO, J. C., 2010, Poblamiento rural tardorromano y altomedieval en Galicia (ss. v-x). Una revisión arqueológica, Archeologia Medievale XXXVII, 285-306.

SÁNCHEZ PARDO, J. C. Y RODRÍGUEZ RESINO, Á., 2009, Poblamiento rural altomedieval en Galicia: balance y perspectivas de trabajo, en J. A. QUIRÓS CASTILLO (ed.), The archaeology of early medieval villages in Europe, Universidad del País Vasco, Vitoria-Gasteiz, 137-147.

SUÁREZ OTERO, J., 1993, Cerámicas pintadas na Galicia medieval: os vasos con pintura branca, Boletín Auriense XXIII, 71-88.

SUÁREZ OTERO, J., GIMENO GARCÍA-LOMAS, R. y FARIÑA BUSTO, F., 1989, La cerámica medieval en Galicia, en J. A. GUTIÉRREZ GONZÁLEZ y R. BOHIGAS ROLDÁN (eds.), La cerámica medieval en el norte y noroeste de la Península Ibérica: aproximación a su estudio, Universidad de León, León, 285-301.

TEJERIZO GARCÍA, C., 2016, Construyendo la casa por los cimientos: consideraciones acerca de la cerámica de la primera Alta Edad Media en la parte central de la cuenca del Duero, en J. A. QUIRÓS CASTILLO y A. VIGIL-ESCALERA (eds.), La cerámica de la Alta Edad Media en el cuadrante noroeste de la Península Ibérica (siglos V-X), Universidad del País Vasco, Bilbao, 229-254.

TEJERIZO GARCÍA, C., 2020a, Cerámicas altomedievales en contextos rurales del centro y noroeste peninsular: secuencia cronotipológica, tecnología y regionalización productiva, Archivo Español de Arqueología 93, 275-301.

TEJERIZO GARCÍA, C., 2020b, El poblamiento en el interior de la Gallaecia entre el final del Imperio Romano y la Alta Edad Media: nuevos datos, nuevas propuestas, Studia histórica. Historia Medieval 38 2, 155-187.
TEJERIZO GARCÍA, C. y QUIRÓS CASTILLO, J. A., 2018, Treinta años de arqueología en el norte de la Península Ibérica. La "otra» arqueología medieval, en J. A. QUIRÓS CASTILLO (ed.), Treinta años de Arqueología Medieval en España, Archaeopress, Oxford, 123-146.

TEJERIZO GARCÍA, C., RODRÍGUEZ GONZÁLEZ, C. y FERNÁNDEZ PEREIRO, M., 2018, Materiais cerámicos tardíos (ss. IV-VI d. C.) no castro de Viladonga, CROA. Boletín da Asociación de Amigos do Museo do Castro de Viladonga 28, 36-52.

TEJERIZO GARCÍA, C., RODRÍGUEZ GONZÁLEZ, C. y FERNÁNDEZ PEREIRO, M., 2019, ¿Continuidad o discontinuidad en los castros del noroeste? Una revisión de la secuencia del yacimiento de Viladonga (Castro de Rei, Lugo), SPAL 28/2, 279-313.

TEJERIZO GARCÍA, C. y VIGIL-ESCALERA GUIRADO, A., 2017, Castro Ventosa y La Cabeza de Navasangil: una revisión de sus secuencias de ocupación y del fenómeno de los asentamientos fortificados altomedievales, Nailos 4, 129-161.

TENTE, C., LANTES SUÁREZ, Ó. y PRIETO MARTÍNEZ, M. P., 2014, A produção cerâmica dos séculos IX a XI na região do Alto Mondego (Portugal), en A. DE MAN y C. TENTE (eds.), Estudos de cerâmica medieval. O norte e centro de Portugal, séculos IX a XII, Instituto de Estudos Medievais, 109-140.

VIGIL-ESCALERA, A., 2003, Cerámicas tardorromanas y altomedievales de Madrid, en L. CABALLERO, P. MATEOS y M. RETUERCE (eds.), Cerámicas tardorromanas y altomedievales en la Península Ibérica. Ruptura y continuidad, Anejos de Archivo Español de Arqueología XXVIII, 371-387.

VIGIL-ESCALERA, A., 2006, La cerámica del período visigodo en Madrid, Zona arqueológica 8, 705-716.

VIGIL-ESCALERA, A., 2007, Algunas observaciones sobre las cerámicas «de época visigoda" (ss. V-IX d. C.) de la región de Madrid, en A. MALPICA y J. C. CARVAJAL (eds.), Estudios de cerámica tardorromana y altomedieval, Granada, 357-382. 
VIGIL-ESCALERA, A., 2013, Las últimas producciones de TSHT en el interior peninsular, Ex Officina Hispana. Cuadernos de la SECAH 1, 11-24.

VIGIL-ESCALERA, A., 2018, Los últimos 30 años de la arqueología de época visigoda y altomedieval, en J. A. QUIRÓS CASTILLO (ed.), Treinta años de Arqueología Medieval en España, Archaeopress, Oxford, 271-294.

VIGIL-ESCALERA, A. y QUIRÓS CASTILLO, J. A., 2016, La cerámica de la Alta Edad Media en el cuadrante noroeste de la Península Ibérica (siglos $V$-X): sistemas de producción, mecanismos de distribución y patrones de consumo, Universidad del País Vasco, Bilbao.

VIGIL-ESCALERA, A. y STRATO, 2013, El registro arqueológico del campesinado del interior peninsular en época altomedieval, en J. A. QUIRÓS CASTILLO (ed.), El poblamiento rural de época visigoda en Hispania. Arqueología del campesinado en el interior peninsular, Universidad del País Vasco, Bilbao, 65-258.

VIGO GARCÍA, A., 2017, Intervención Arqueolóxica en Os Castros (Mondoñedo, Lugo), Memoria técnica inédita.

VV. AA., 1998, A guide to the classification of medieval ceramic forms, Medieval Pottery Research Group, Londres.

WICKHAM, C., 2005, Framing the Early Middle Ages: Europe and the Mediterranean, 400-800, Oxford University Press, Oxford.

XUSTO RODRÍGUEZ, M. y EGUILETA FRANCO, J. M., 1992, Arqueología medieval gallega: consideraciones metodológicas, Gallaecia 13, 273-302. 
